\title{
A Review: Study of Integral Abutment Bridge with Consideration of Soil-Structure Interaction
}

\author{
Maryam Naji* (D), Ali Akbar Firoozi ${ }^{\text {b }}$, Ali Asghar Firoozi ${ }^{c}$ \\ aDepartment of Civil Engineering, Higher Education Complex of Saravan, Saravan, Iran. Email: naji_af@yahoo.com \\ ${ }^{b}$ Department of Civil Engineering, Faculty of Engineering \& Technology, University of Botswana, Gaborone, Botswana, \\ Email: a.firoozi@gmail.com \\ 'Tarh Sazeh Estehkam (T.S.E) Consulting Engineering, Tehran, Iran, Email: mehran.firoozi@gmail.com \\ * Corresponding author
}

http://dx.doi.org/10.1590/1679-78255869

\begin{abstract}
Bridges are one of the most critical parts of transportation networks that may suffer damages against earthquakes. Also, seismic responses of most bridges are significantly influenced by soil-structure interaction effects. Taking out expansion joints in the bridges may cause many difficulties in design and analysis due to the complexity of soil-structure interaction and nonlinear behavior. The secondary loads on an IAB include seismic load, temperature variation, creep, shrinkage, backfill pressure on back wall and abutment, all of which cause superstructure length and stress variations in girder changes. The purpose of this study is to recognize the most effective parameters of analysis IABs. Findings show that the backfill material behind the $I A B s$ has a significant effect on the performance of IABs. Using a compressible material behind the abutments would enhance the in-service performance of IABs. Finally, behaviour of abutment may be greatly affected by thermal load and soil pressure. Thermal expansion coefficient significantly influences girder axial force, girder bending moment, and pile head/abutment displacement.
\end{abstract}

\section{Keywords}

Integral Abutment Bridge (IAB); Finite Element; Seismic Analysis; Earth Pressure Distribution; Soil Pile Interaction.

\section{Graphical Abstract}
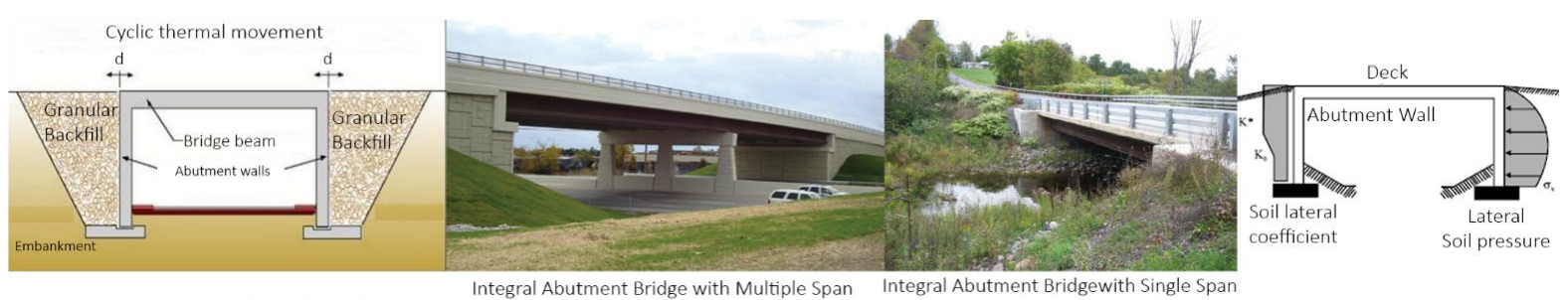

Separation due to the cyclic pressure on the soil over a time of period
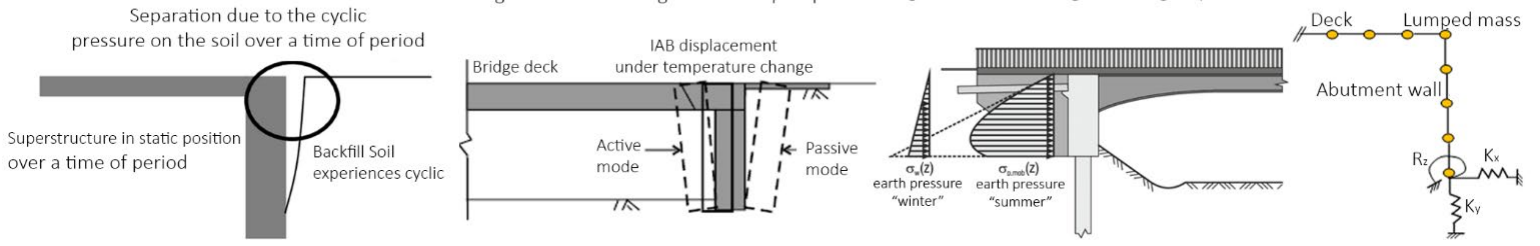


\section{INTRODUCTION}

Expansion joint system is a standard feature of traditional bridges and it comes with roller support, abutment bearings as well as various structural releases to account for cyclic occurrences when the bridge expands or contracts due to thermal conditions, creep and shrinkage [1-3]. The emergence of joint problems came in the 1960s as traffic loads increased in speed, volume, and weight. To maintain and replace expansion joints consumes a considerable amount of money spent. Joints and bearings in traditional bridges have emerged as major sources of bridge maintenance problems and costs [4, 5]. Fig. 1 shows an example of a conventional bridge with expansion joint. Addition, Fig. 2 shows an example of damaged expansion joints and their effects on the substructure.

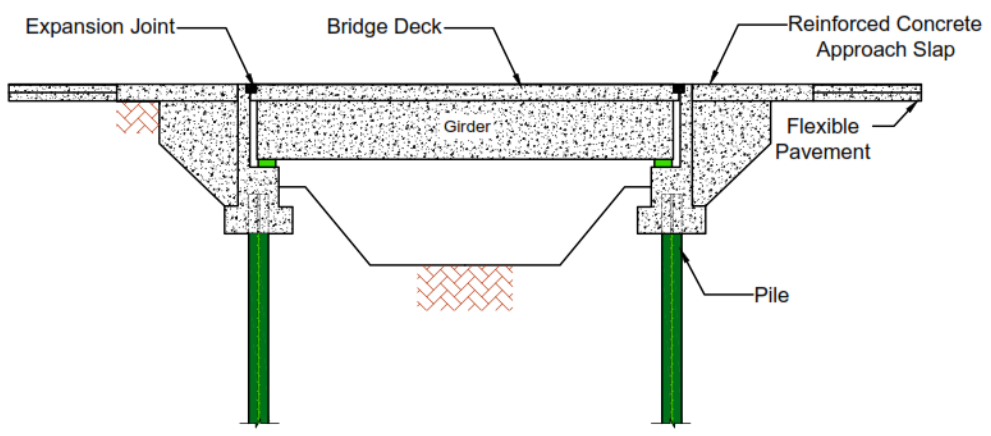

Fig. 1 Conventional bridge [3]
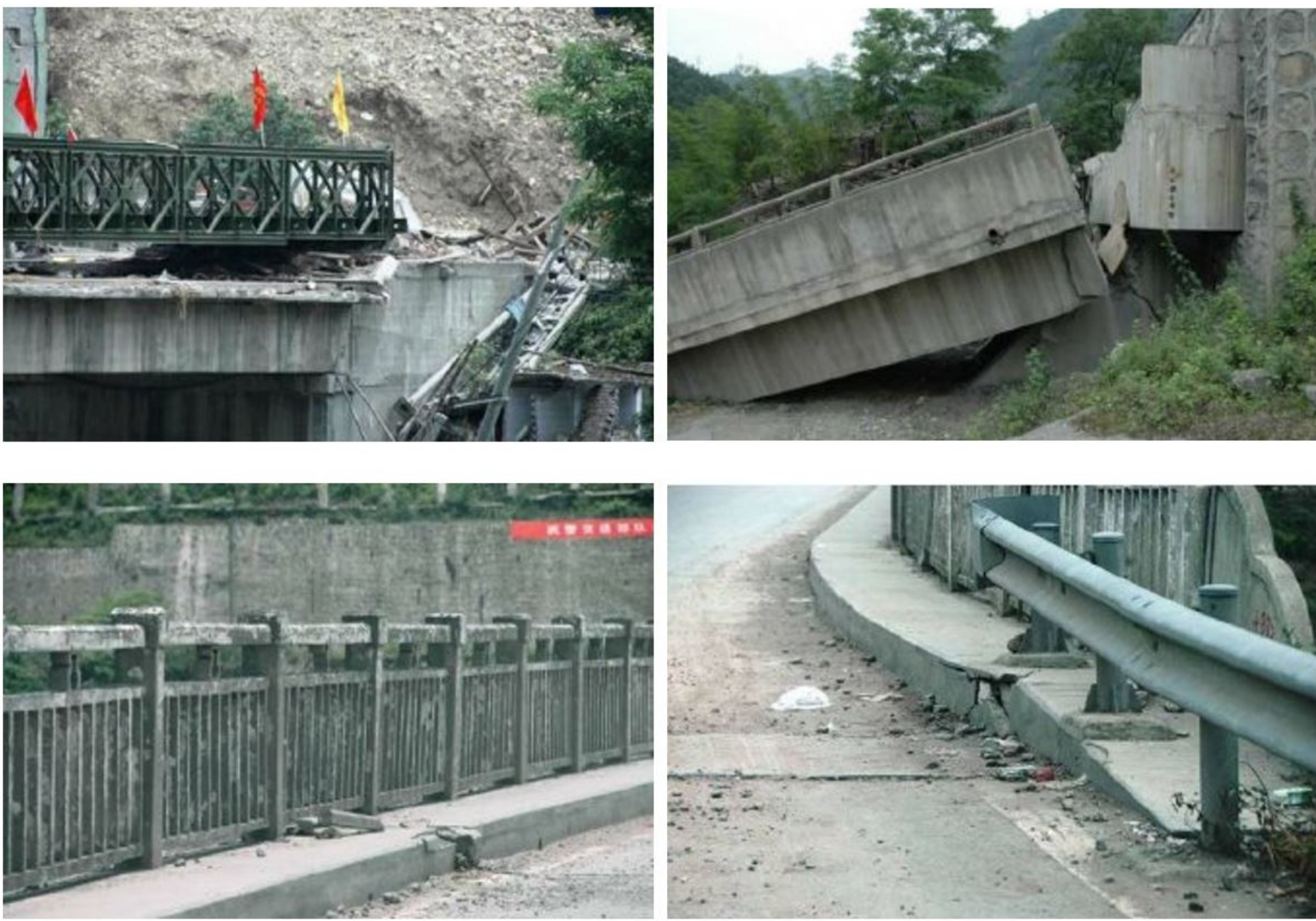

Fig. 2 Damaged expansion joints and their effects on the substructure [6]

The rehabilitation or retrofitting of bridge deck joints was studied by Greimann and Wolde-Tinsae [7]. The concept of IAB and semi IAB was developed in an attempt to eliminate expansion joints. Generally, IABs, are single (Figure 3) or multiple span structures with flexible foundations (single row of steel piles) in which the girders are integrated with the 
abutments. Expansion joints and moveable bearings on the extremes of the deck are replaced with control joints located at the end of the approach slab, where joint leakage does not adversely affect the structure. When the foundation has greater flexibility and less resistance to longitudinal movement, stress from longitudinal forces can be minimized [8-10]. Figure 4 shows the integral abutment connection details used by the Pennsylvania Department of Transportation [11].

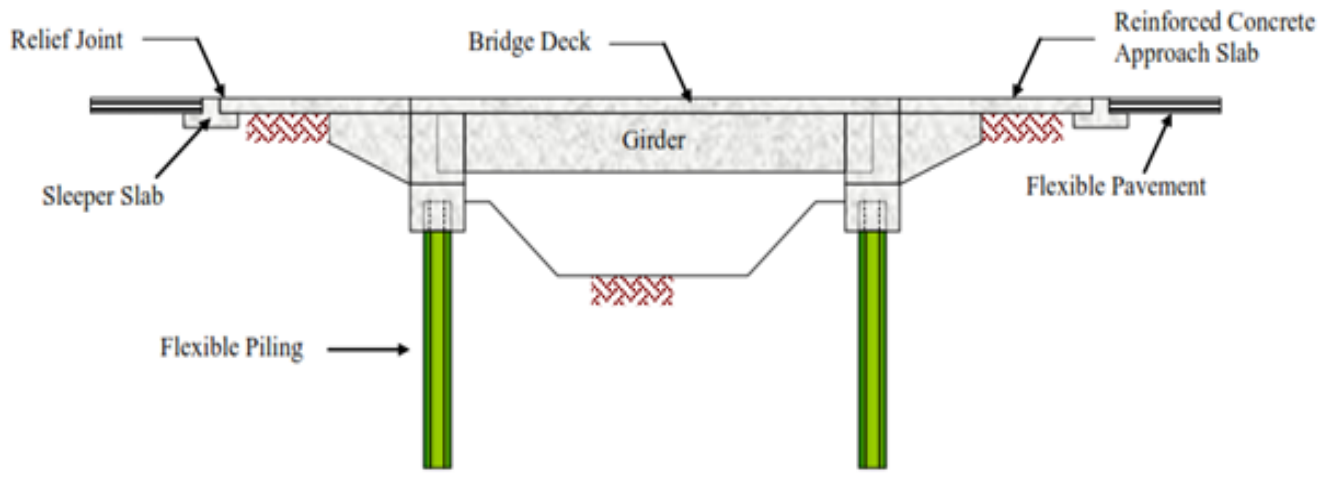

Fig. 3 Typical IAB with single span [7]

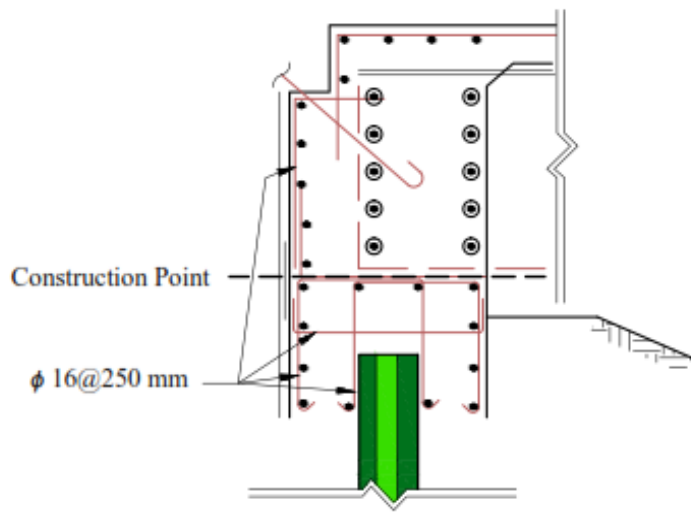

Fig. 4 Standard IAB Details [11]

\section{Performance of IAB}

Some researchers have studied the performance of IAB [12-18]. They showed that IABs exhibit adequate performance but many of them are highly stressed. For example, an abutment supported by a solitary row of piles is viewed to have the flexibility to withstand longitudinal displacement of the superstructure and dynamic end rotations brought about by the movement of vehicle traffic. The steel piles of such an abutment are regularly exposed to axial and flexural stresses close or equal to excess of yield stresses. The stress at the top of the pile is sufficient to initiate yield stress in the steel but not sufficient to cause the formation of a plastic hinge [18-21]. However, for longer IABs, such piling stresses, if large enough, may result in the formation of plastic hinges that may limit the flexural resistance of the piles to additional superstructure elongation. Lack of moment of the abutments can cause higher stresses in the deck than it is designed to sustain as the bridge attempts to expand or contract but is restrained. At the same time, the laterally supported piles should retain their capacity to sustain vertical loads [22-24].

A numerical study conducted by Greimann et al. [25] explored the consequence predrilled oversized holes have on abutment pile response. A finite element model of beam-column elements and nonlinear soil springs was employed for the study, which revealed that oversized holes, particularly those drilled to significant depths did much to alleviate overstressing the steel H-piles (HP) used under the abutment. Piles without oversized holes in harder soils such as stiff clay or compacted fill were shown to develop plastic hinges much quicker for prescribed transverse tip displacement than their counterparts with predrilled holes. IABs have proven to be economical and effective in eliminating joint maintenance issues, but they can also be problematic. When the bridge expands and contracts during thermal loading, soil at the interface is disturbed. Ground subsidence adjacent to abutments (under approach slabs) has been observed. Subsidence behind the abutment wall can cause structural problems in the approach slab if bending loads are significant 
as vehicles pass over the slab. In the long term, these bridges can cause lateral earth pressures to build upon the abutments because of the soil mechanics phenomenon known as ratcheting [26, 27].

IABs have been in use for many years, but there is still no comprehensive design procedure. Each state highway department in the United States manages its own integral abutment program and establishes guidelines with regard to design and construction. Not having a organized design and construction procedure leads to variations in the analysis, design and construction practices of IABs between states. However, AASHTO LRFD [28] is the most widely accepted bridge design code in the United States and provides performance criteria for a general IAB design. The AASHTO LRFD [28] does not requie any detailed design or analysis methods. In addition, special load combinations for IABs are not given even though boundary conditions of IAB's are different from conventional jointed bridges [29]. To reduce passive pressure developed in abutment backfill by an expanding integral bridge, a number of controls, devices, and procedures are used. These include limiting bridge length, structure skew and the vertical penetration of abutments into embankments; using select granular backfill and uncompacted backfill; providing approach slabs to prevent vehicular compaction of backfill or to permit the use of backfill voids behind abutments; using embankment benches to shorten wing walls and using suspended turn back wing walls. . additionally, used are semi-integral abutment designs to removepassive pressure under bridge seats. Longitudinal forces in superstructures are linked to abutment pile foundations resisting longitudinal movement. Therefore, pile stresses area dealt with by limiting the foundation of integral bridges to just one row of slender vertical piles; limiting the pile types; orienting the weak axis of HP piles normal to the direction of movement; using pre-bored holes packed with fine granular material for piles; providing an abutment hinge to control pile flexure; limiting structure skew and using semi-integral abutment designs for longer bridges to minimize foundation restraint to longitudinal movement. Finally, the most significat objectives of this study is to recognize the most effective parameters of analysis IABs by considering soil-structure interactions [30, 31].

\subsection{Conventional Model}

Conventionally, an IAB is idealized as a continuous beam frame structure if no soil reactions are considered, which could be statically solved manually since the moment distribution method has been developed [32]. In this way, the continuous frame is solved but only with regard to the deck abutment joints design. However, the piers of the model are often idealized as simple roller hinge supports. In designing an IAB, what must be considered is the effect of the loads in the end, on the assumption a completed structure, is taken into account. This particular method utilizes simple structure models to analyze the IAB. The result is a faster application when manually done. As a result, many structural engineers have used it for designing IABs that provide the effects of gravitational loads (Figs. 5 and 6) [33, 34]. However, the structural model doesn't show how the bridge actually behaves or indicates the impact of change of loading conditions and the soil-structure interactions while computers began to be widely used in the design and analysis of structures, finite element method was the most widely practiced method, as it could simulate complicated structural behavior under complicated structural loads, such as live loads, earth pressure and effect of temperature variations.

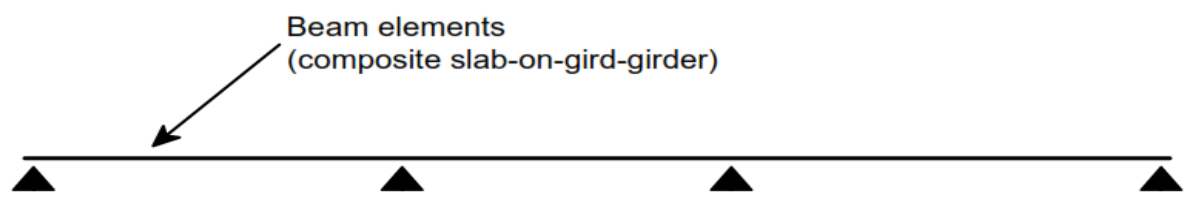

Fig. 5 Conventional model for deck design [33]

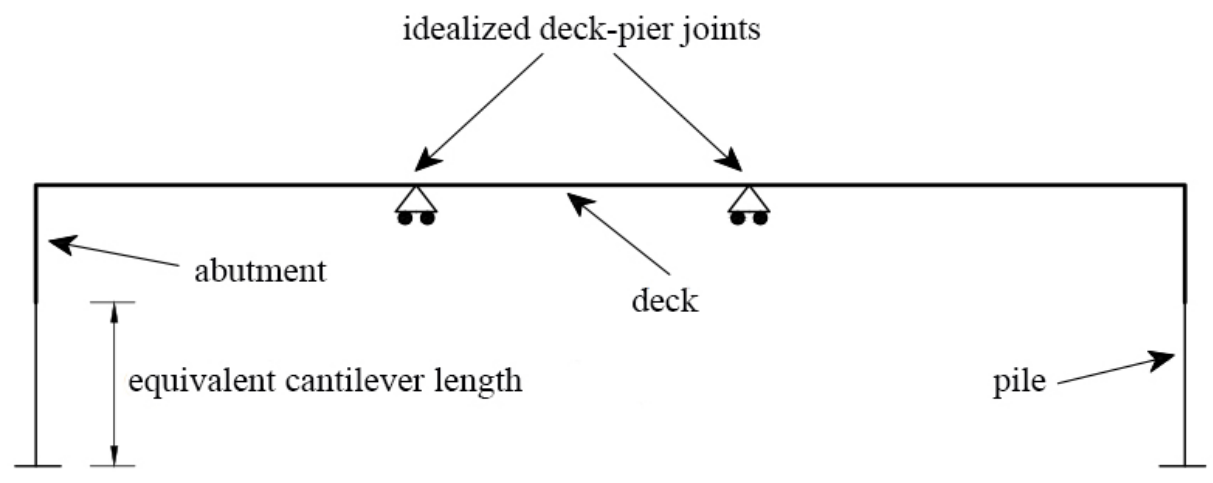

Fig.6 Conventional model for deck-abutment design [33] 


\subsection{Finite Element Model}

The finite element method is a technique for analyzing complicated problems by notionally cutting up the continuum of the prototype into a number of small elements with different material properties and section characteristics of different structural components, which are connected at discrete joints called nodes. Nowadays, most nonlinear structural problems can be simulated in computer programs of the finite element method. There are many finite element model schemes which have been developed, both two dimensional and three dimensional, with and without springs, piles of full length, and equivalent cantilever length. An efficient finite element model employing nonlinear soil elements at the back wall, abutment, piles, and joints can be implemented using a three dimensional or two-dimension model [35-37]. Comparison between the 2D and the more complex 3D analyses shows the difference within six percent on average results [38]. A 2D modeling is therefore sufficient in analyses and predicting bridge behavior within the scope of the study. Two finite element models are shown in Figs. 7 and 8.

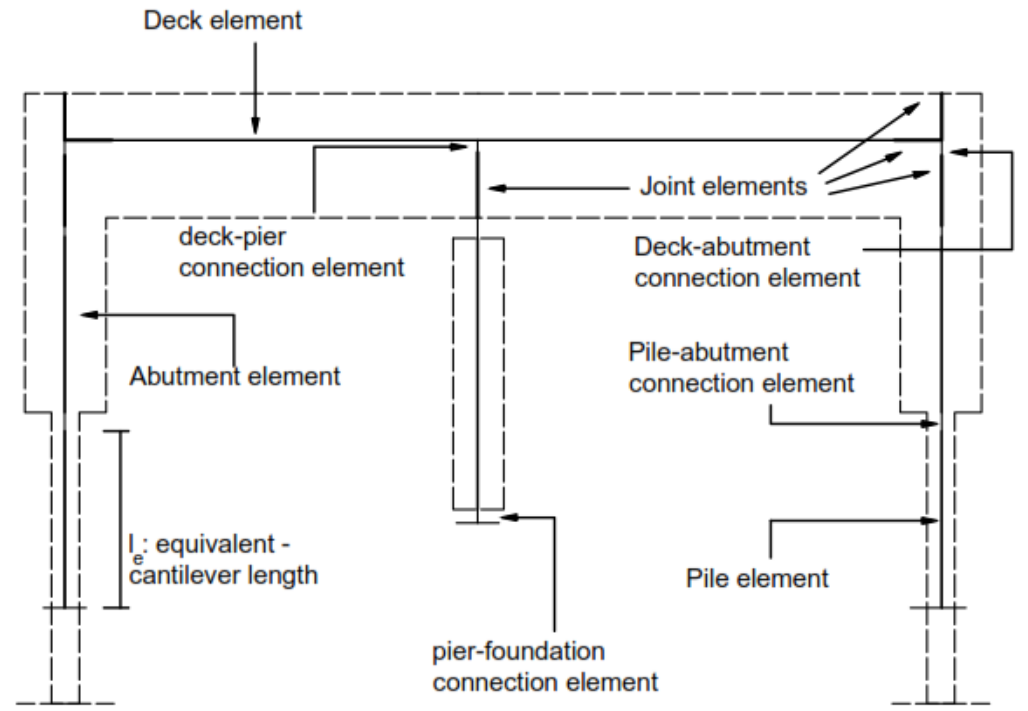

Fig. 7 Finite element model for construction stage proposed [34]

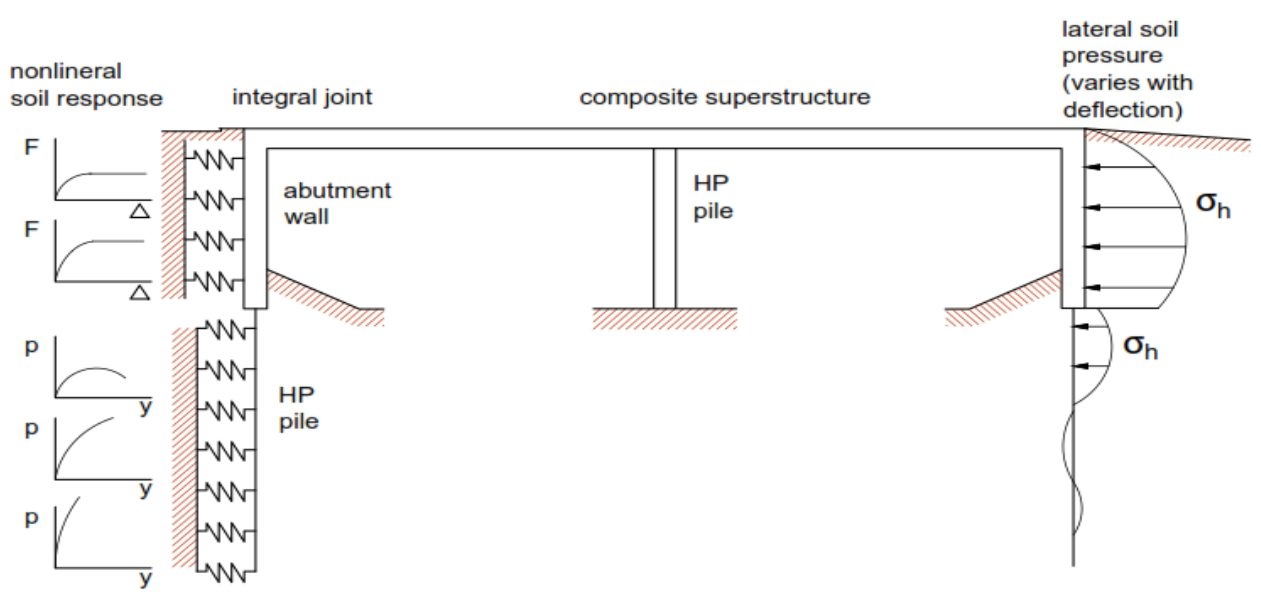

Fig.8 Soil modeling in finite element model [34]

Generally, finite element model should implement structural elements (beam and plates), an algorithm to account for soil-structure interaction where foundation soil system elements (i.e. driven piles) could go beyond yielding in some IAB system, and thermal loading capabilities in the finite elements $[39,40]$.

\section{Soil-Structure Interaction of IAB}

Although the concept of IAB provides many advantages and avoids many complications in construction, the furthermost important concern in analyzing and designing an IAB is the possible reaction of soil to the rear of abutment walls and nearby piles. When a bridge is thermally expanded, there are substantial degrees of force exerted by the soil 
and this can significantly impact the whole bridge structure. Such inherently nonlinear activity of soil is dependent on the amount and form of displacement of the wall, which brings about translation and rotation. The problem affects to the soil-structure and is stated as a drag of Soil-Structure Interaction (SSI), whereby there is independence independence in the amount and form of soil and deformations in structure and stresses [41]. However, soil conditions can vary from loose to dense states, the soil pressure that builds up behind the abutment will increase more than four times and axial forces in the bridge deck increase by about $50 \%$ while bending moments in the composite deck increase by about 40 percent [42-45].

\subsection{Soil Support Interaction}

Generally, the integral bridge concept has been proven to be less expensive to construct for wide-ranging span lengths; it has also been shown to be successful from the technical point of view as it eliminates problems of joint and bearings expansion. However, it may be troubled by geotechnical issues, which are potentially the result of reaction of the complicated structure of the soil to relative movement of the bridge abutment and surrounding retained soil. Primarily, as this movement is due to both natural and seasonal variations in weather and other longitudinal movements such as seismic loads, it is a potential problem for all integral bridges [46-48].

\subsection{Conventional Models on Earth Compression}

A lateral earth pressure coefficient, $K$ is used to explain the pressure soil will exert $[49,50] . K$ is the ratio of lateral (horizontal) pressure to vertical pressure $\left(K=\sigma_{h} / \sigma_{v}\right)$ (Fig. 9). It's believed that lateral earth pressure is in direct proportion to the straight up compression at all assumed purpose within the contours. There is a dependence of $K$ on the properties of the soil and its historical record. There are three categories of horizontal earth compression coefficients: $K_{0}$ at rest, $K_{a}$ active, and $K_{p}$ passive. Expecting lateral earth pressure can be based on several theories, empirically-based or analytically derived.

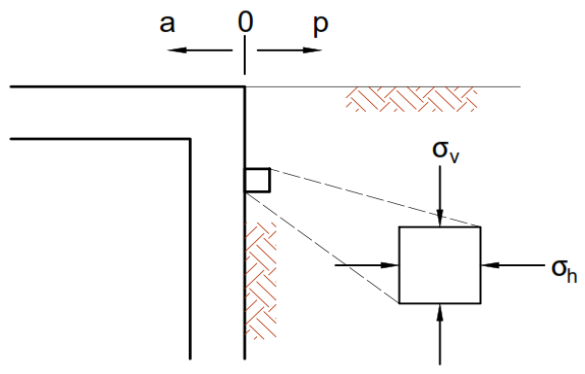

Fig. 9 Stress state behind the abutment [50]

Coulomb in 1776 was a pioneer in the study of problems associated with horizontal earth pressures and their impact on retaining structures. He used the idea of Limit Equilibrium, that takes into consideration the failing back soil as an independent entity to determine the control of the lateral earth pressure. Such control at failure in extension or compression are used to show the $K_{p}$ and $K_{a}$ respectively as indicated in Equations 1 and 2 . Should the problem be undetermined, there there must be an analysis of those surfaces that might potentially fail in order to locate the critical surfaces that could exert maximum or minimum force on the wall. Mayniel in 1808 further developed Coulomb's Equations to include wall friction, represented by Muller-Breslau in 1906 who proceeded to generalize Mayniel's Equations to a non-horizontal backfill and a non-vertical soil wall interface as represented by the angle from the vertical $[51,52]$.

$$
\begin{aligned}
& K_{a}=\frac{\cos ^{2}\left(\phi^{\prime}-\theta\right)}{\cos ^{2} \theta \cos (\delta+\theta)\left(1+\sqrt{\frac{\sin \left(\delta+\phi^{\prime}\right) \sin \left(\phi^{\prime}-\beta\right)}{\cos (\delta+\theta) \cos (\beta-\theta)}}\right)^{2}} \\
& K_{p}=\frac{\cos ^{2}\left(\phi^{\prime}+\theta\right)}{\cos ^{2} \theta \cos (\delta-\theta)\left(1-\sqrt{\frac{\sin \left(\delta+\phi^{\prime}\right) \sin \left(\phi^{\prime}+\beta\right)}{\cos (\delta-\theta) \cos (\beta-\theta)}}\right)^{2}}
\end{aligned}
$$


$\phi^{\prime}$ is the angle of internal friction of soil, $\theta$ is back face inclination of the structure, $\beta$ is slope inclination and $\delta$ is angle of friction soil-structure.

\subsubsection{Rankine Theory}

Rankine in 1857 developed a theory as a stress field solution for the prediction of active and passive pressure. It made the assumption that there is no cohesion in the soil, no friction in the wall, the interface of soil wall is vertical, a plainer failure surface for the soil to move on and the angle of the generated force parallels the surface of the backfill. The Equations for active and passive lateral earth pressure coefficients are provided below and it should be noted that the angle $\phi^{\prime}$ of shearing resistance of the soil and the backfill is inclined at an angle $\beta$ to the horizontal [51].

$$
\begin{aligned}
& K_{a}=\cos \beta \frac{\cos \beta-\sqrt{\cos ^{2} \beta-\cos ^{2} \varphi^{\prime}}}{\cos \beta+\sqrt{\cos ^{2} \beta-\cos ^{2} \varphi^{\prime}}} \\
& K_{p}=\cos \beta \frac{\cos \beta+\sqrt{\cos ^{2} \beta-\cos ^{2} \dot{\varphi}}}{\cos \beta-\sqrt{\cos ^{2} \beta-\cos ^{2} \dot{\varphi}}}
\end{aligned}
$$

For the case wherever $\beta$ is 0 , the above Equations are simplified to:

$$
\begin{aligned}
& K_{a}=\tan ^{2}\left(45-\frac{\phi^{\prime}}{2}\right) \\
& K_{p}=\tan ^{2}\left(45+\frac{\phi^{\prime}}{2}\right)
\end{aligned}
$$

However, once the abutment moves into the approach fill there is a buildup of passive earth pressure that is dependent on the displacement. The use of full passive pressure without regard for the displacement is not conservative as it decreases the flexural effects of dead and live load in the bridge girders. Some researchers [53-55] proposed modified coefficients based on Rankine's law. The passive earth pressure coefficients were thought to be reduced by multiplying Rankine's passive coefficients. It was recommended to be applied in most of IABs with a single span, or small and medium spans. This simplified method is not widely used and has been found to be different from other analyses.

\subsubsection{Earth Pressure Distribution in Design}

The lateral pressure on the abutments cannot be determined simply from statistical calculations, and the stresses at the soil abutment interface are governed by a complex soil-structure interaction defined in terms of cyclic movement (expansion and contraction) of the bridge engineering and geologists [56-59]. Based on these factors, numerical studies provided some empirical relations between lateral pressure and movement of the wall.

\subsection{Recommended Design in United states America}

Most bridges within the united states America are designed in accordance with the specifications of the American Association of State Highway and Transportation Officials (AASHTO). It is reported that AASHTO determines horizontal soil pressure on the bridge abutments according to Rankine's active soil pressure. The pressure is limited to $4.8 \mathrm{kN} / \mathrm{m}^{2}$ for a meter of height support, and is $K_{a}$ expected toward 0.3 uniforms triangular. Rankine's load distributions square measure employed in planning the soil pressure on integral bridge abutments within the USA and are used in designing the soil pressure on integral bridge abutments in the USA and Canada, while also some of the agencies do not consider soil pressure. However, based on available variations of earth pressure coefficient as a function of structural displacement of experimental data and finite element analyses proposed a practical linear relationship [60,61].

$K=K_{0}+\phi d \leq K_{p}(7)$

where $d$ is that the displacement of the IAB toward the backfill soil and $\phi$ is is the slope of the earth pressure variation shown in figure 10 and the $\phi$ varies according to the soil type of the backfill. 


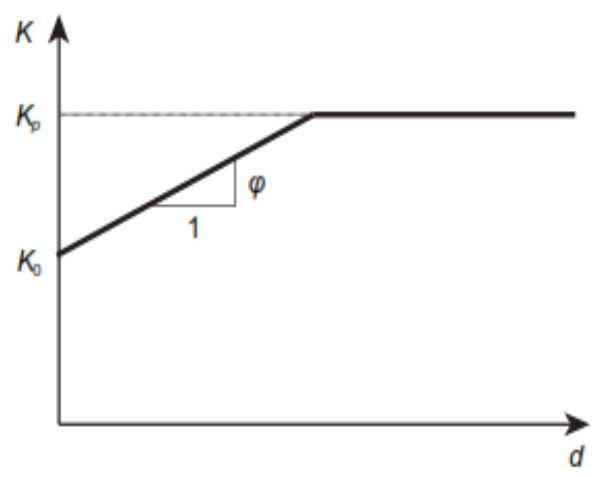

Fig. 10 Variation of passive soil pressure factor [59]

Results from full-scale wall tests performed at the University of Massachusetts, shown there is reasonable agreement between the predicted average passive earth pressure response of standard compacted gravel borrow and the curves of $\mathrm{K}$ against $\delta / H$ for dense sand found in design manuals. For the design of IABs, the coefficient of horizontal earth pressure $\mathrm{K}$ depends on the relative wall displacement, $\delta / H$ that is displayed in Fig. 11 . When using compacted gravel borrow backfill the pressure coefficient $\mathrm{K}$ shall be estimated using Equation 8.

$K=0.43+5.7\left[1-e^{-190\left(\frac{\delta}{H}\right)}\right]$

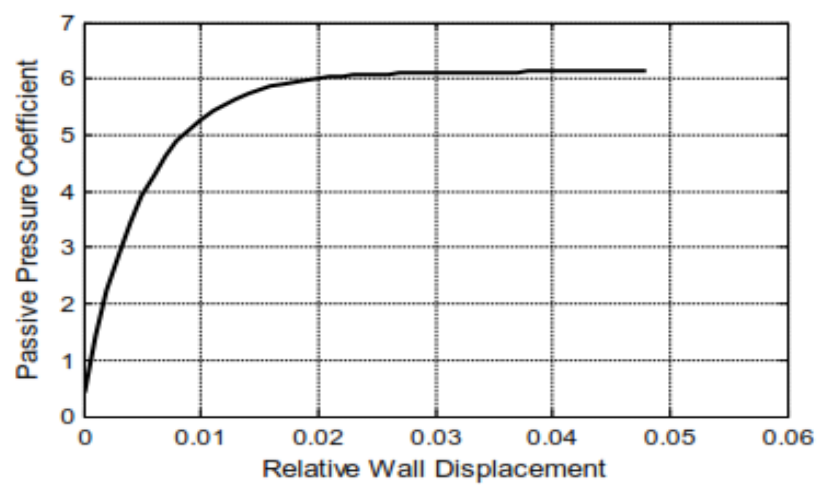

Fig.11 Passive pressure coefficient [61]

\subsection{Recommended Design in England}

From the experiments on cyclic stress of backfill soil on a concrete wall pinned to the strip footing [62, 63] and according to the Highway Agency Design Manual for Roads and Bridges (2003), for the lateral earth pressure that is shown in Fig. 12, where the distribution is derived as a uniform stress ratio $\mathrm{K}^{\wedge *}$ from the surface to a depth of one half the height of the wall and a uniform pressure $\left(\gamma K^{*} \mathrm{H}\right) / 2$ over the bottom half of the wall. The recommended Equation to be calculated $K^{*}$ is:

$K^{*}=K_{0}+\left(\frac{d}{0.03 H}\right)^{0.6} K_{p}$

where, $\mathrm{H}$ is the retained height, $\mathrm{d}$ is the thermal displacement of the top of the abutment, $\mathrm{K} \_0$ is the at-rest earth coefficient and the passive earth pressure coefficient $K_{p}$ is based on $\delta=\phi^{\prime} / 2$ and taken from European standard (Eurocode 7) [64]. 


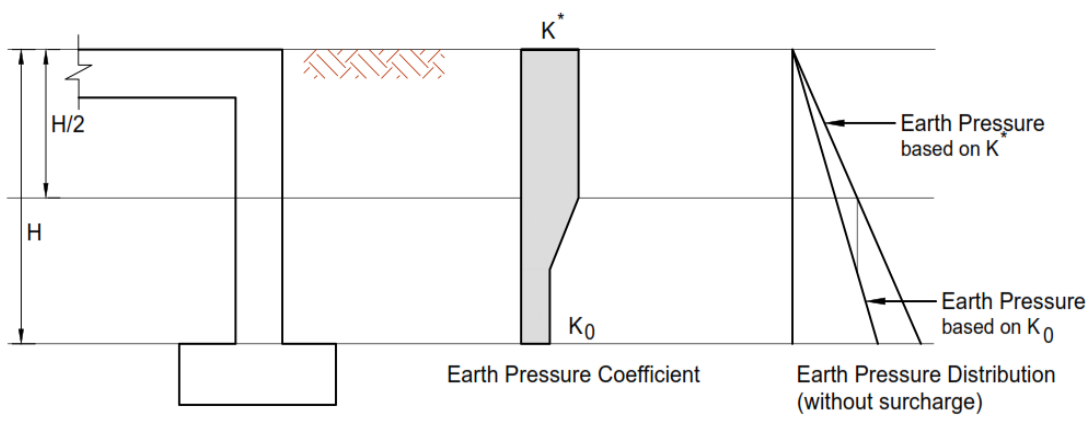

Fig. 12 Earth pressure distribution for frame abitment [64]

\subsection{Discrete earth Pressure Distribution in Design}

The soil reaction distribution on the wall is basically nonlinear, and there is difference in depth, quantity, and type of wall displacement. Depending on the composite bridge deck's relative flexural stiffness, the foundation piles of the abutment wall and horizontal stiffness of the soil to the rear of the wall and beside the piles, the extent and way the wall is deformed can change. This subsequently influences the degree of the pressure and quantity of soil exerted by the soil reaction behind the wall. With the application of finite element method in structural analysis, and the concept of a series of separated "Winkler" springs, where one level's deflection of the wall need not necessarily impact the degree of the reaction force at another level; the discrete nonlinear springs have been utilized for the stimulation of the soil-structure interaction to the rear of the abutment wall and beside the pile. There are some kinds of nonlinear force-deflection relations of the springs applied behind the abutment that is widely used in finite element analysis. These curves normally comprise regimes that are active and passive and typically employed for horizontal translation and rotation about the base [65].

In Eurocode 7 [64], the boundary conditions of the earth earth pressure on a vertical wall, resulting from weight density, need to be calculated according to Bell's relations. Intermediate values of earth pressure of the rest limit state may be derived from linear interpolation and intermediate values of passive earth pressure between the rest state and the limit state may be achieved by parabolic interpolation, while the limit movement values to reach the limit pressure are different according to the types of wall movement. Conventionally Coulomb or Rankine theories have been used for the design of integral abutments. Displacement dependent earth pressure theories are also being investigated to arrive at a closer estimate of the earth pressure generated during the cyclic loading of the abutments. Clough and Duncan [66] reported that the specified displacement for full passive pressure development is $\Delta / h 0.04$ for loose sand and 0.01 for thick sand. Here, $\Delta$ is the straight movement at the highest of a rigid wall thanks to rotation or translation and $\mathrm{h}$ is that the height of the wall. For the look of essential supports, the most movement $\Delta$ at the top of the support due to thermal variations is calculated by supercilious that the total bridge movement is divided similarly between each abutment as presented in Figure 13:

$\Delta=\frac{1}{2} L \alpha \Delta T(10)$

where $L$ is the length of the continuous bridge, $\alpha$ is the coefficient of thermal extension and $\Delta T$ is the difference between the temperature during construction and the maximum or minimum temperature expected at the site.

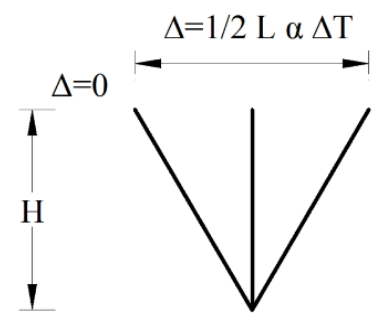

Fig. 13 The maximum displacement $\Delta$ at the topof the abutment [67]

Besides, one widely employed curve set for loose, medium and dense cohesionless granular materials, is based on finite element analyses by Clough and Duncan [66] and may be found in many style manuals like NCHRP report No.343 
that's shown in Fig. 14, and Foundation Engineering Handbook. Another popular set of design curve is available in Canadian Foundation Engineering Manual (CGS) [67] (Fig. 15), and the U.S. Section of the Navy [68] (Fig. 16).

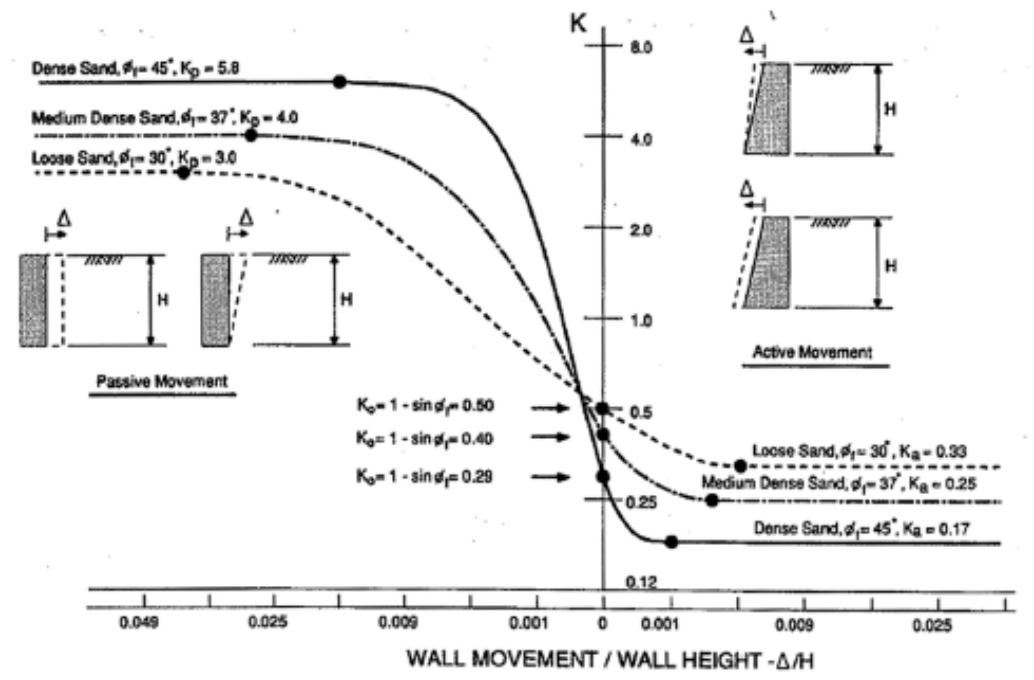

Fig. 14 Relationship betweenwall displacement and earth pressure sand in NCHRP [65]

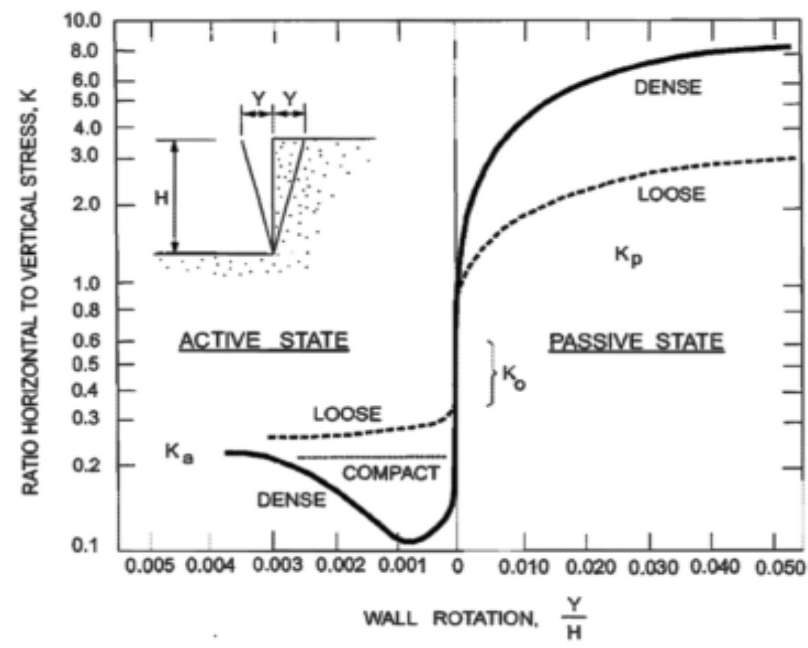

Fig. 15 Relationship between deformation by increasing soilpressure [65]
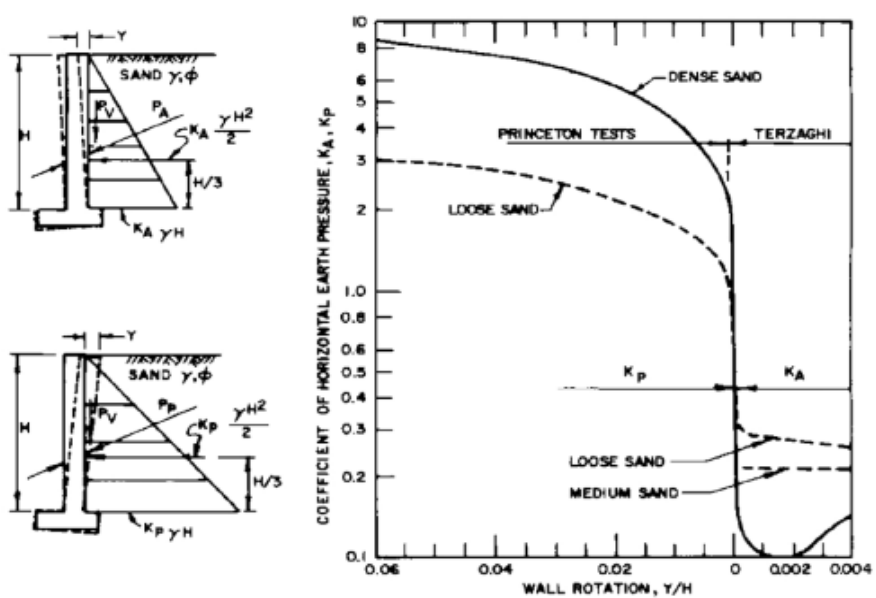

Fig. 16 Effect of wall movement on wall pressure Naval Pressure Facilities Command [65] 
As can be seen, these three families of curves are familiar. They can be generalized into elastoplastic nonlinear relations as shown in Fig. 17 for determining $K_{a}, K_{p}$, NCHRP and NAVFAC recommend applying Rankine's theory log spiral graphs for regular and regular backfill configuration, whereas Coulomb's experimental failure wedge methodology is Rankine's concept to be usually additional conservative on active pressure, while logarithmic spiral is to be a realistic description of passive pressure $[69,70]$.

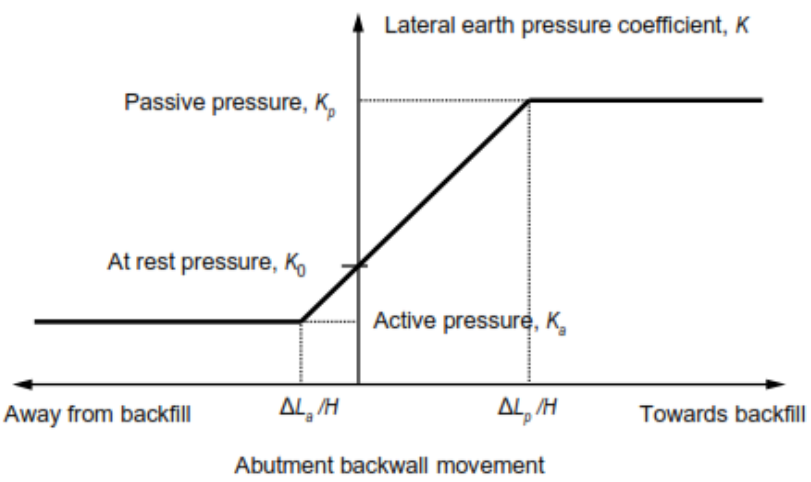

Fig. 17 Elastoplastic diagram of nonlinear springs restraining the abutment back wall [65]

As can be observed in Figs. 15 and 16 active and passive areas are accessible for loose and dense sand. The proposed curves of NCHERP, NAVFAC and CGS have different coefficient $k$ for loose and dense sand in active and passive positions. Their magnitudes of $\Delta L / H$ that are required reach the minimum active and maximum passive earth pressure are sumurized in Table 1. From the comparison, the NCHRP values are moderate between these three recommendations and widely used in engineering practices $[67,71,72]$.

Table 1 Estimated magnitudes of movements required to reach minimum active and maximum passive earth pressure conditions $[67,71,72]$

\begin{tabular}{ccccccc}
\hline \multirow{2}{*}{ Category of backfill } & \multicolumn{2}{c}{ NCHRP } & \multicolumn{2}{c}{ CGS } & \multicolumn{2}{c}{ NAVFAC } \\
\cline { 2 - 7 } & dynamic & inactive & dynamic & inactive & dynamic & inactive \\
\hline Thick sand/dense cohesionless & 0.001 & 0.01 & 0.001 & 0.02 & 0.0005 & 0.002 \\
Slack sand/soft cohesionless & 0.004 & 0.04 & 0.004 & 0.06 & 0.002 & 0.006 \\
Compressed clay/stiff cohesive & 0.01 & 0.05 & 0.01 & 0.02 & 0.01 & 0.02 \\
Compressed clay/loose cohesive & 0.01 & 0.05 & 0.02 & 0.04 & 0.02 & 0.04 \\
\hline
\end{tabular}

\section{Soil Pile Interaction}

The preference is for piles of IAB as opposed to spread footings because of erosion and vertical deformation. The piles themselves at working loads exhibit essentially elastic behavior, but the surrounding soil may be in states ranging from elastic to plastic and furthermore, may be subject to cyclic degradation. Hence, design of such structural members represents a complex problem of soil-structure interaction. For IAB, the general belief is that a rotationally and transnationally stiff foundation leads to greater superstructure loads when there is longitudinal movement. To maximize the horizontal and rotational flexibility of the pile head, piles for an IAB foundation are placed into pre augured deep holes, which are then backfilled with loose sand. It is also common practice to install piles, with their weak axis of bending parallel to the bridge centerline [73-77]. p-y curves, that show how the lateral soil pressure (horizontal force per unit length of pile) is related to the corresponding lateral pile displacement is the focus of this chapter, $p$ is lateral force and $y$ is lateral displacement; $f-z$ curves explain how skin friction (vertical force per unit length of pile) is related to the relative vertical displacement of pile and soil. $f$ is friction on surface of pile and $z$ is vertical displacement, and $q-z$ curves indicate how the bearing stress at the pile tip is related to the pile tip settlement. $q$ is vertical force on effective pile tip area. All these curves assume the nonlinearity of the soil behavior again, the Winkler model assumes that these springs are uncoupled, that is, that motion at one spring does not affect another (Fig. 18). 


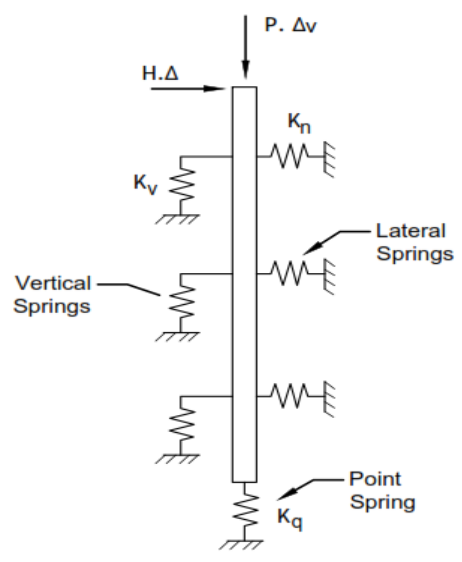

Fig. 18 Soil-pile system

\subsection{Terzaghi's Concept}

Terzaghi and other researchers made an assumption that the coefficient of horizontal pile reaction $K_{h}$ is a constant $[78,79]$ :

$K_{h}=\frac{p}{y}$

where, $\mathrm{p}$ is is the pressure on the pile; $\mathrm{y}$ is the horizontal displacement of pile, and $K_{h}$ the coefficient of horizontal reaction is often assumed to be constant for clay soils or to vary linearly with depth for granular soils and sand. The assumption has been widely used in analytical studies on pile resistances and its preliminary design.

\subsection{Empirical p-y Curves}

Matlock [80] proposed a well-known family of p-y curves, which were based in research on laterally loaded piles in soft clay involving extensive field testing with an instrumented pile, experiments with laboratory models and the parallel development of analytical methods and correlations. Figure 19 shows the characteristic shape of the soft clay $p$-y curves for the static loading case, which can be represented by using a parabolic Equation as:

$p=\left\{\begin{array}{c}0.5\left(\frac{y}{y_{50}}\right)^{\frac{1}{3}} \\ p_{u}\end{array}\right.$

$y_{p}=8 y_{50}$

where, $y_{50}$ is lateral movement of soil corresponding to $50 \%$ of ultimate lateral soil resistance and calculated as $y_{50}=2.5 \varepsilon_{50} B$, and $\mathrm{y}$ is is the lateral movement of soil. $\mathrm{B}$ is diameter of pile. The ultimate lateral soil resistance $p_{u}$ is considered as Equation 14.

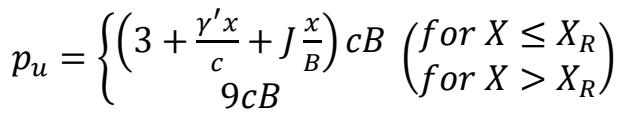

$x_{R}=\frac{6 B}{\left(\frac{\gamma^{\prime} B}{c}+J\right)}$

where $p_{u}$ is ultimate lateral soil resistance corresponding to the ultimate shear stress of soil $c_{u}, \gamma^{\prime}$ is the effective unit weight, $\mathrm{x}$ is the depth from ground surface, $\mathrm{c}$ is the undrained shear strength of the clay, and $\mathrm{J}$ is a constant frequently taken as 0.5 . The lateral movement of soil corresponds to $50 \%$ of ultimate soil resistance where $\varepsilon$ _50is the strain of soil corresponding to half of the maximum deviator stress. In Fig. 19, another part of the diagram shows the characteristic shape of the soft clay $p-y$ curves for the cyclic loading case. The main difference between static and cyclic loading is that 
the soil resistance for cyclic loading at large strain levels is decreased. Construct the $p$-y curve in the same manner as for short term static loading for values of $p$ less than $0.72 p_{u}$. If the unit weight and shear strength are constant, then:

$Z_{R}=\frac{6 c_{u} b}{\left(\gamma^{\prime} b+J c_{u}\right)}$

If the unit weight and shear strength vary with depth, the value of $Z_{R}$ should be computed with the soil properties at the depth where the $\mathrm{p}$-y curve is desired. When the depth to the $\mathrm{p}$-y curve is greater than or equal to $Z_{R}$ then $\mathrm{p}$ is equal to $0.72 p_{u}$ for all values of $y$ greater than $3 y_{50}$ and when the depth of the $p$ - $y$ curve is less than $Z_{R}$ then the value of $p$ decreases from the $0.72 p_{u}$ at $y=3 y_{50}$ to the value given by the following expression at $y=15 y_{50}$.

$p=0.72 p_{u l t}\left(\frac{Z}{Z_{R}}\right)$

The value of $p$ remains constant beyond $y=15 y_{50}$.

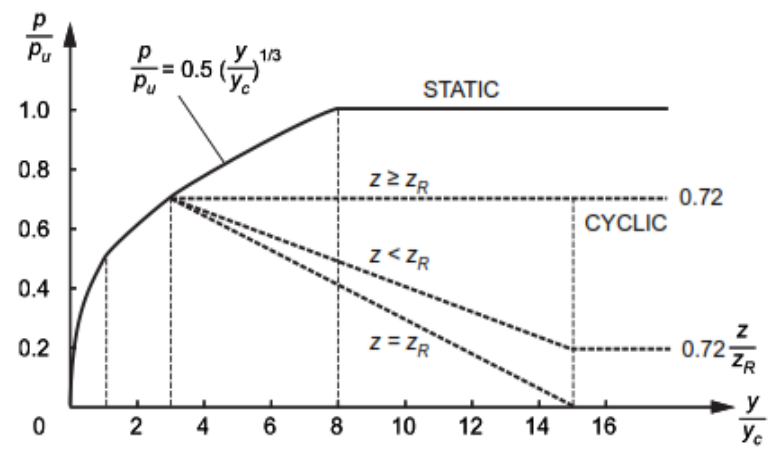

Fig. 19 Typicalp-y curves for laterally loaded piles in soft clay [79]

Another family of p-y curves for piles in stiff clay was constructed by Reese [81] as shown in Fig. 20 and Cox [82] carried out an experiment on two $0.6 \mathrm{~m}$ diameter, flexible driven piles embedded in a deposit of submerged, dense, fine sand. Reese et al. [83] used the results of the above experiment to develop a procedure for obtaining $p$-y curves for sands. The characteristic shape of the $p$-y curve is composed of three straight lines and a parabolic curve (Fig. 21). In this approach, the initial modulus of subgrade reaction and ultimate soil resistance are needed to develop p-y curves. They suggested suitable values for the initial modulus of subgrade reaction for different relative density of sands.

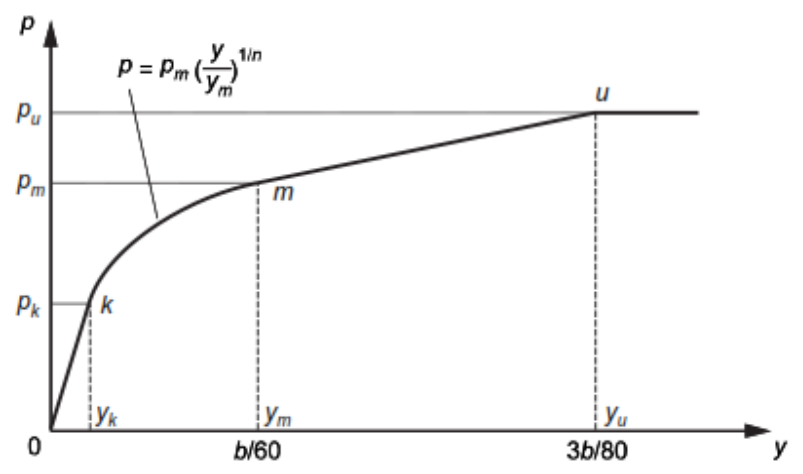

Fig. 20 Typical $p$-y curves for piles in stiff caly [81] 


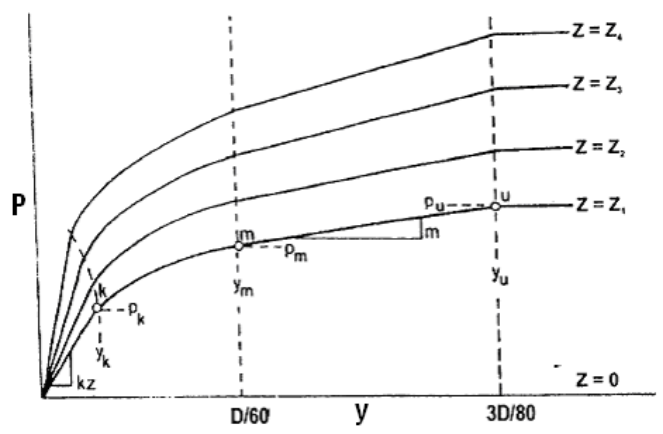

Fig. 21 Typical $p-y$ curves for sand [83]

\subsection{Elasto Plasticity Models}

Considering the nonlinear behavior, a simplified elastic and perfectly plastic behavior can be assumed. The only soil spring properties needed for the design method are the ultimate resistance and the initial stiffness. Also, other researchers [84-87] had developed the modified Ramberg-Osgood model that accommodates loading and unloading of the pile during cyclic loading, which is used to approximate the $p-y, f-z$, and $q-z$ soil resistance and displacement curves for use in the finite element solution. For example, for $p$-y curves, the model could be expressed as:

$p=\frac{K_{h} y}{\left[1+\left|\frac{y}{y_{u}}\right|^{n}\right]^{1 / n}}$

$y_{u}=\frac{p_{u}}{K_{h}}$

where, $K_{h}$ is the initial stiffness; $p$ is the generalized soil resistance; $p_{u}$ is the ultimate soil resistance; $n$ is the shape parameter of pile and $y$ is the generalized displacement. The constants can be empirically determined from basic soil properties (Fig. 22).

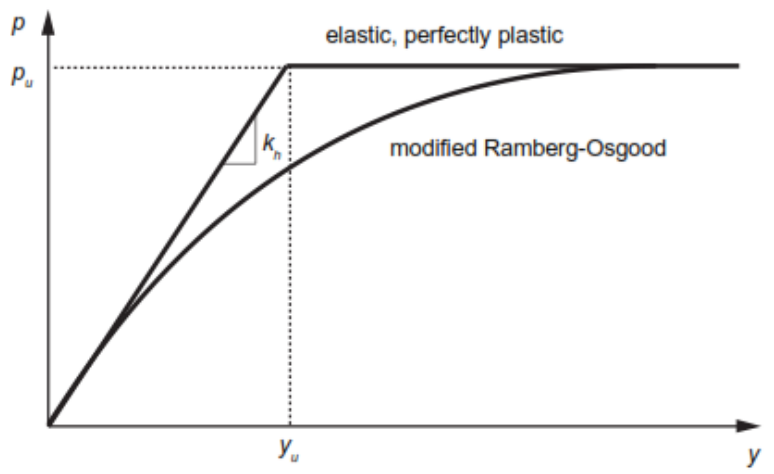

Fig. 22 Typical elastoplastic $p-y$ curves [87]

\subsection{API Design Method}

Designing methods for IAB assume that soil spring exhibits equal linear response despite the widely-known fact that it is nonlinear and hysteretic. Current soil resistance methods to predict soil resistance is, API methods, Hansen's and Broms approaches offer varying predictions of soil resistance for the similar earth environments [88-91]. Of these ways, the foremost refined square measure API ways utilized by the industry in nonlinear soil modeling for lateral pile loading. In general, API ways square measure typically utilized in engineering apply. several of today's laptop programs to model lateral pile behavior follow the yanked crude oil Institute (API) pointers used for planning mounted offshore platforms (API 2000). The API ways square measure supported the p-y curves which studied by Matlock [80] for soft clay, Reese et.al. [80] for stiff clay, and Murchison, J.M., and O'Neill [92] for sand. These ways square measure represented and adopted within the sections that follow. 


\subsection{Soil Resistance Designed for Clay}

The nonlinear sideways earth resistance deflection associations for piles in soft clay, for the static load and dybamic loading, could be generated from Table 2:

Table 2 Soil resistance deflection under static and dynamic load [93]

\begin{tabular}{|c|c|c|c|c|c|}
\hline \multirow{2}{*}{\multicolumn{2}{|c|}{ Static load }} & \multicolumn{4}{|c|}{ Cyclic load } \\
\hline & & \multicolumn{2}{|c|}{$\mathrm{X}>\mathrm{X}_{R}$} & \multicolumn{2}{|c|}{$\mathrm{X}<\mathrm{X}_{\mathrm{R}}$} \\
\hline$y / y_{50}$ & $p / p_{u}$ & $p / p_{u}$ & $y / y_{50}$ & $p / p_{u}$ & $y / y_{50}$ \\
\hline 0.0 & 0.00 & 0.00 & 0.0 & 0.00 & 0.0 \\
\hline 1.0 & 0.50 & 0.50 & 1.0 & 0.50 & 1.0 \\
\hline 3.0 & 0.72 & 0.72 & 3.0 & 0.72 & 3.0 \\
\hline 8.0 & 1.00 & 0.72 & $\infty$ & $0.72 X / X_{R}$ & 15.0 \\
\hline$\infty$ & 1.00 & & & $0.72 X / X_{R}$ & $\infty$ \\
\hline
\end{tabular}

where, $\mathrm{p}$ is actual lateral resistance $(\mathrm{kPa}) ; p_{u}$ is ultimate resistance $(\mathrm{kPa}) ; \mathrm{y}$ is real lateral deflection $(\mathrm{mm}), y_{50}=2.5 \varepsilon_{50} D, \varepsilon_{50}$ is a strain which happens at half the maximum stress on laboratory undrained compression test of undistributed soil samples; $\mathrm{X}$ is underground depth ( $\mathrm{mm}$ ); $X_{R}$ is the depth from below soil surface to the bottom of the reduced resistance zone $(\mathrm{mm})$. In the case of loads that are laterally static, the stiff clay's maximum bearing capacity $p_{u}$ would exceed that of soft clay. Because clay can deteriorate rapidly, due to cyclic loadings, the maximum resistance level can be significantly decreased, a factor to be carefully considered in cyclic design. Moreover, even though stiff clays also have nonlinear stress-strain curves and subsequent $p$-y curves for cyclic loads, good design should consider how rapidly the load capacity of stiff clays can deteriorate at large deflections (Fig. 23).

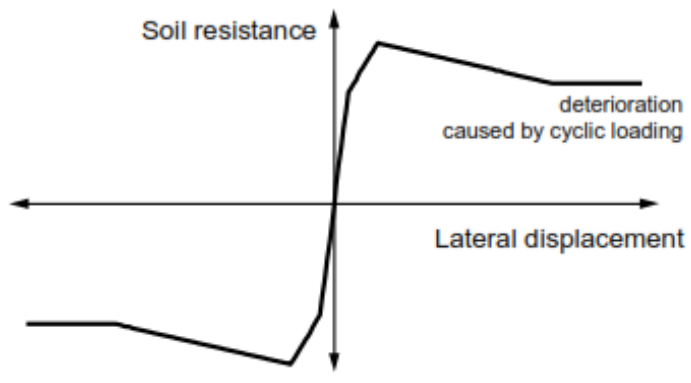

Fig. 23 Typical soil resistance of clay [93]

\subsection{Soil Resistance used for Sand}

ultimate lateral bearing capacity for sand can be determined from the recommended equations in API guidelines [93]. The $\mathrm{p}$-y curves could also be calculable at any specific depth $\mathrm{H}$, as indicated below and shown in Figure 24:

$P=A p_{u} \tanh \left[\frac{k H}{A p_{u}} y\right]$

where, A should be considered for cyclical or static loading state; $p_{u}$ is eventual bearing capacity at depth $\mathrm{H}(\mathrm{kN} / \mathrm{m}) ; \mathrm{k}$ is the initial modulus of subgrade response $\left(\mathrm{kN} / \mathrm{m}^{3}\right)$, which can determined as a function of angle of internal friction $\left(\phi^{\prime}\right)$, as shown in Figure 25.

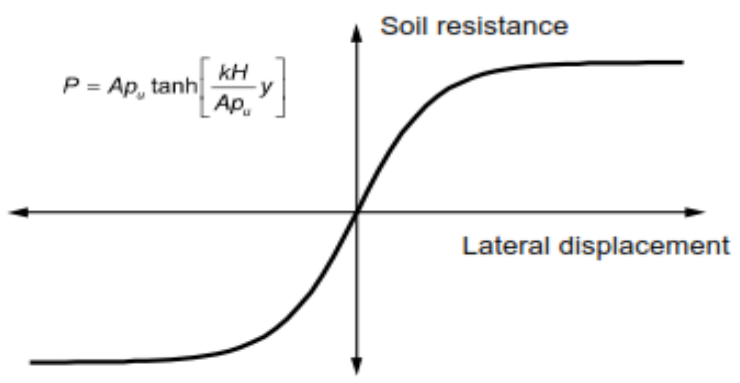

Fig. 24 Typical soil resistance of sand [93] 


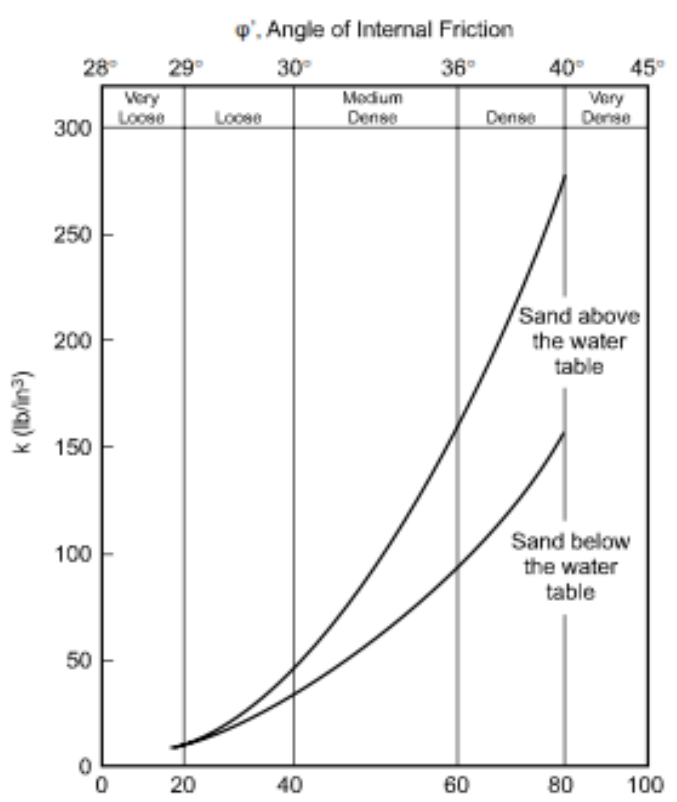

Fig. 25 Initial modulus of subgrade reaction of different sand [93]

\subsection{Equivalent Cantilever Approach}

Embedded piles are represented with comparable cantilever method, as a column with a base fixed at a depth below the ground (Fig. 26). The notation is the same for both the fixed and pinned head conditions. The pinned head condition is shown in Fig. 27. The pile's embedded length underground is symbolized as $l$, whereas $l_{u}$ is that the length above the ground. The equivalent embedded length $l_{e}$ is that the depth from soil surface to the fastened base of the equivalent cantilever. the entire length of the equivalent cantilever is that the length $l_{u}$ plus $l_{e}$ and delineate by L. Long embedded pile in soil features a depth below that the horizontal displacements at the pile head have negligible effects. A critical length, $l_{c}$ that represents this depth, is calculated. For anything more than this length, lateral displacements and bending moments are about four percent of those at the pile head. If a pile is longer than $l_{c}$, the pile would seem to be infinitely long [94]. For soil uniform subgrade reaction modulus, the critical length is selected as:

$l_{c}=4 R$

$R=\left(\frac{E I}{K_{h}}\right)^{1 / 4}$

where $E$ is that the modulus of elasticity of pile, $l$ is moment of inertia and $K_{h}$ is coefficient stiffness of soil. Most piles utilized in apply square measure longer than their vital length and behave as "flexible" piles. $l_{c}$ is a parameter of the pile and soil system and is not a physically identifiable length. Equivalent cantilevers can be used to calculate the forces in the pile and the bridge superstructure. For example, an equivalent cantilever can be determined such that its maximum moment would be equal to the maximum moment in a real pile. However, the complete moment diagram below the ground surface cannot be determined with the same equivalent cantilever. Three different equivalencies are considered in the development of the design method. They are based on the soil pile system's horizontal stiffness, maximum moment of the pile, and the pile's elastic buckling load. 


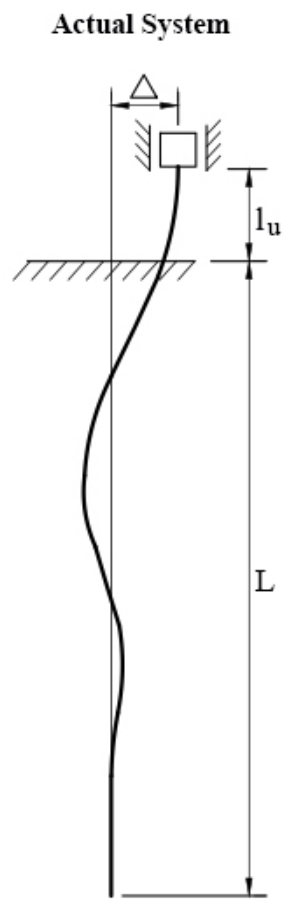

Equivalent Cantilever

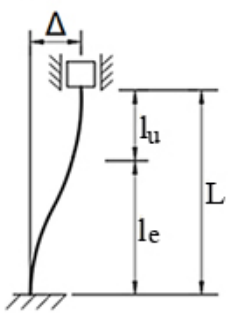

Fig. 26 Cantilever idealization of the pile for the fixed head state [94]

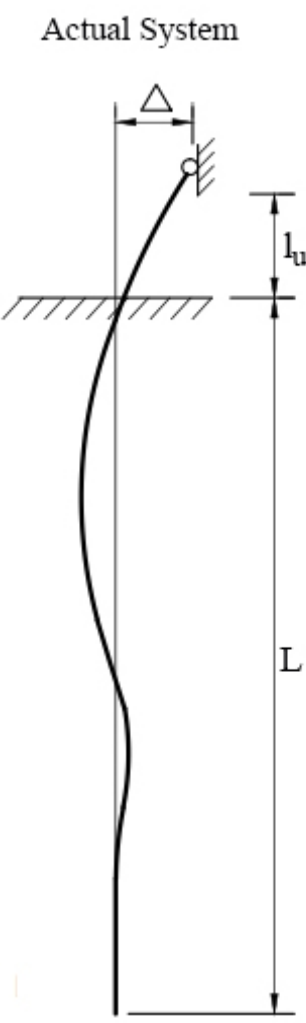

Equivalent Cantilever

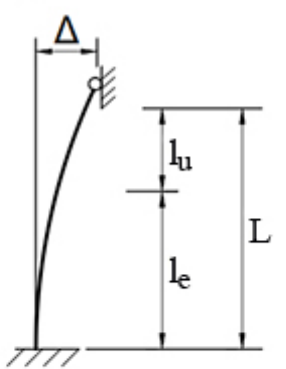

L

Fig. 27 Cantilever idealizationidealism of the pile for the pinned head state [94]

For each equivalency, the boundary condition at the pile head is either fixed (no rotation) or pinned (no moment) (Figs. $26 \& 27)$. The horizontal displacement at the top of the equivalent system corresponds to the longitudinal expansion or contraction of the bridge superstructure at the integral abutment. The equations for determining the equivalent embedded length are expressed in different equivalencies in the Table 3 [95]. 
Table 3 Equations for an equivalent embedded length of piles [95]

equation

\section{Horizonta}

stiffness

moment

buckling

Horizontal

stiffness

moment

buckling

Corresponding implanted length

\section{Fixed-head pile}

$$
\frac{l_{e}}{l_{c}}=\sqrt[3]{\frac{256\left(\frac{l_{u}}{l_{c}}\right)^{4}+256 \sqrt{2}\left(\frac{l_{u}}{l_{c}}\right)^{3}+192\left(\frac{l_{u}}{l_{c}}\right)^{2}+48 \sqrt{2\left(\frac{l_{u}}{l_{c}}\right)+12}}{256\left(\frac{l_{u}}{l_{c}}\right)+64 \sqrt{2}}-\frac{l_{u}}{l_{c}}}
$$

$$
\frac{l_{e}}{l_{c}}=\sqrt{\frac{128\left(\frac{l_{u}}{l_{c}}\right)^{4}+128 \sqrt{2}\left(\frac{l_{u}}{l_{c}}\right)^{3}+96\left(\frac{l_{u}}{l_{c}}\right)^{2}+24 \sqrt{2}\left(\frac{l_{u}}{l_{c}}\right)+6}{128\left(\frac{l_{u}}{l_{c}}\right)^{2}+64 \sqrt{2}\left(\frac{l_{u}}{l_{c}}\right)+16}}-\frac{l_{u}}{l_{c}}
$$

$$
\frac{l_{e}}{l_{c}}=\left(\frac{2 \pi}{\beta_{e} l_{u}}-1\right) \frac{l_{u}}{l_{c}}
$$

Pinned- head pile

$$
\begin{aligned}
& \frac{l_{e}}{l_{c}}=\sqrt[3]{\left(\frac{l_{u}}{l_{c}}\right)^{3}+\frac{3 \sqrt{2}}{4}\left(\frac{l_{u}}{l_{c}}\right)^{2}+\frac{3}{8}\left(\frac{l_{u}}{l_{c}}\right)-\frac{l_{u}}{l_{c}}} \\
& \frac{l_{e}}{l_{c}}=\sqrt[\frac{l_{u}}{l_{c}}]{\frac{3}{16\left(Q_{M}\right)_{\max }\left[\frac{32 \sqrt{2}}{3}\left(\frac{l_{u}}{l_{c}}\right)^{3}+16\left(\frac{l_{u}}{l_{c}}\right)^{2}+4 \sqrt{2}\left(\frac{l_{u}}{l_{c}}\right)+1\right]}} \\
& \frac{l_{e}}{l_{c}}=\left(\frac{\pi}{0.7 \beta_{e} l_{u}}-1\right) \frac{l_{u}}{l_{c}}
\end{aligned}
$$

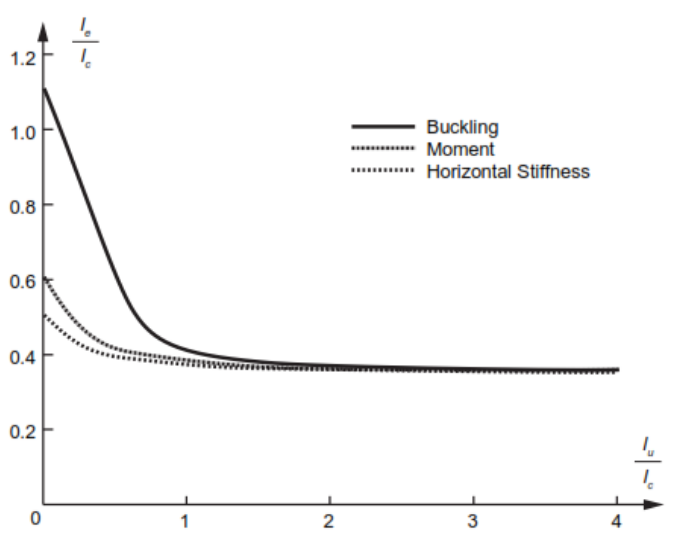

Fig. 28 Equivalent cantilevers for fixed head pile embedded in uniform soil [95]

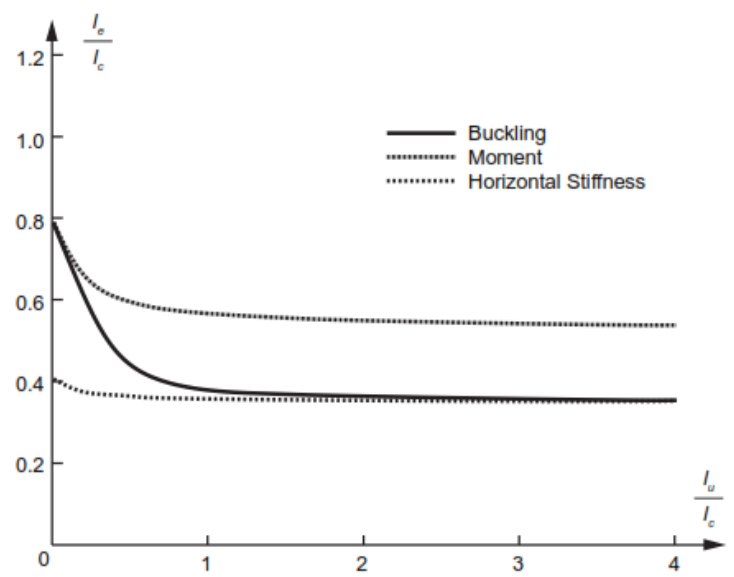

Fig. 29 Equivalent cantilevers for pinned head pile embedded in uniform soil [95] 
These equations are plotted in a non-dimensional form and pinned head piles are embedded in uniform soil as presented in Figs. 26 and 27, respectively. As can be seen from Figures 28 and 29, an unfilled predrilled hole significantly reduces the equivalent embedded length until the hole is approximately $l_{c}$ deep, that is, $l_{u} / l_{c}$ equals approximately one. Below that depth, the effective length remains essentially constant over the range used for most IABs. For piles implanted in a non-uniform soil, the equivalent soil stiffness develops to determine the equivalent cantilevers. This equivalent cantilever method currently used in the Massachusetts Highway Department bridge design manual MassDOT (2005) provides a reasonable approximation to moments in pile in engineering practice. To gain insight into IAB performance and design, in these models, besides the soil-structure interaction, there are still two important issues worth discussing: pile length and plastic hinge for nonlinear analyses [95-98].

\subsection{Piles Length in Modeling}

In FE models, some use the full length of piles, while others use an equivalent cantilever approach mentioned before. In fact, because of the assumption of equivalencies in equivalent cantilever approach, equivalent length of piles cannot reflect the behavior of piles. For example, when the equivalency of horizontal stiffness of soil pile system is made, the horizontal displacement of pile tip and abutment is the same, rather than the maximum bending moment and its distribution is hardly the same. The maximum bending moment, usually occurring at the depth above the equivalent depth of fixity, is measured utilizing the flexural strength of the pile and the ultimate pressure distribution of the soil. It is necessary, therefore, to assume an additional concentrate of plastic hinge rotation at the position of maximum bending moment, which would make the model more complicated. Therefore, to completely understand the pile behavior, different equivalent models are considered. Moreover, according to equation 22, for multi-layered or non-uniform soil conditions, there is also the difficulty of determining equivalent soil stiffness, which artificially assumes a starting value of equivalent stiffness and calculation iterations and convergence does not verify if the pile consists of different parts of different outer shapes. Although the equivalent cantilever approach is quite useful in analytical models and appropriate for evaluating the lateral strength and ductility demand of a yielding soil pile system, the full length model will be used in the following finite element model, which is capable of evaluating the pile and the structure behavior in both ultimate state and service state [98-101].

\subsection{Plastic Hinges in Modeling}

As a frame structure, the bending moments always attain the materials' ultimate capabilities in joints when the loadings are intense enough. Therefore, most finite element models use certain kinds of elements to simulate the joints. Because the IAB are structures of enough redundancy, the bridge would not fail when one or two plastic hinges are formed. Even in some structures, the plastic hinges are designed to form where the forces can be released. Performancebased seismic engineering emphasizes simulating the nonlinear response of a structural system exposed to seismic ground motion and accepting that there will be the formation of plastic hinges in frame members. Precise and computationally efficient numerical models that show cyclic loading of plastic hinges in beam-column elements are needed for simulating the response and evaluating a structural system's performance. Finite element models for nonlinear material response of beam-column members fall into two categories: concentrated plasticity and distributed plasticity $[16,45]$. In concentrated plasticity, the nonlinear behavior of a beam-column member is grouped into rotational springs at the ends of one linear elastic element. The rotational spring is represented by moment-rotation $(M-\theta)$ curve. For structural members, the moment-curvature $(M-\theta)$ diagram of sections (Fig. 30 can be calculated under certain axial moment interaction by integrating the constitutive models for fragile and ductile materials at sections of the element. Therefore, the lengths of plastic hinges have to be identified for converting $M-\phi$ curves to $M-\phi$ curvatures (Fig. 31). In girders, using the approach, the length of the plastic hinges I_p can be determined from the concrete properties:

$l_{p}=\frac{G_{f}^{c}}{0.6 f_{c}^{\prime}\left(\varepsilon_{20}-\varepsilon_{c}+0.8 f_{c}^{\prime} / E_{c}\right)}$

where $f_{c}^{\prime}$ is the concrete compressive strength; $\varepsilon_{c}$ is peak compressive strain; $E_{c}$ is elastic modulus; and $\varepsilon_{20}$ is strain equivalent to twenty percent of the compressive strength; $G_{f}^{c}$ is concrete fracture energy in compression. Alternatively, the plastic hinge length can be specified using an empirically validated relationship, such as the equation for reinforced concrete members:

$l_{p}=0.08 L+0.022 f_{y} d_{b}$ 
where, $\mathrm{L}(\mathrm{m})$ is the length of the member; and $f_{y}(\mathrm{MPa})$ and $d_{b}(\mathrm{~m})$ are yield strength and diameter, respectively, of the longitudinal bars.

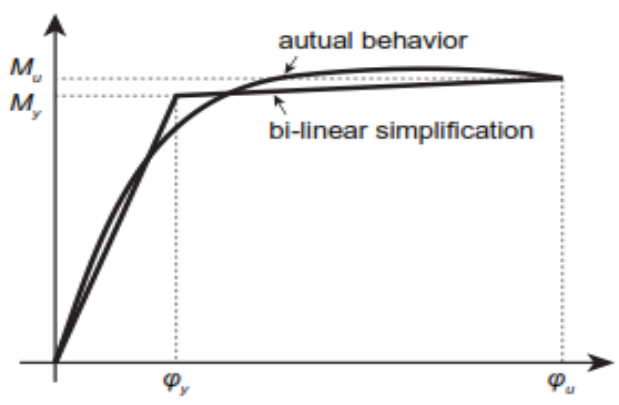

Fig. 30 Moment curvature relation [102]

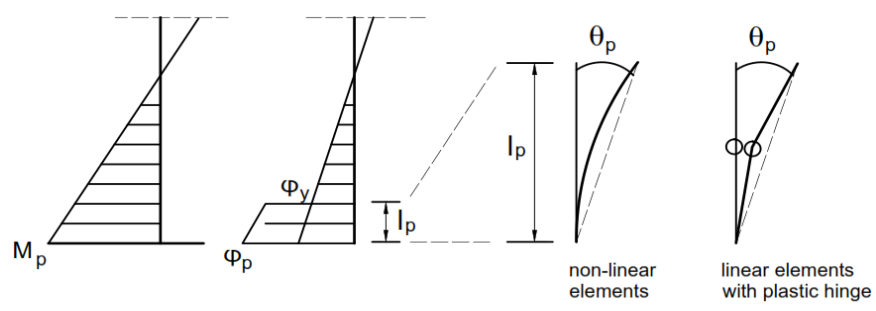

Fig. 31 Plastic hinge simulation [102]

In piers, according to the European Committee for Standardization (CEN 2005), the plastic length can be calculated through equation 25 , that is similar form to equation 24 .

$L_{p}=0.1 H_{p}+0.015 f_{y} d_{b}(25)$

where $H_{p}$ is the distance from plastic hinge section to the section of zero moments. The length of plastic hinges in piles can be estimated also through equation 25 , since the concentrated hinge model has been adopted to derive analytical models to determine the ductility of piles in several selected limit states. Besides, a pile varies with the development of soil plasticity around the pile, the distributed hinge model uses plastic hinges within a possible zone of plasticity in the pile $[103,104]$. The plastic zone of a pile is considered to form at a certain depth $L_{p}$ below the ground surface:

$L_{p}=\sqrt{\frac{2\left(M_{u}-M_{y}\right)}{p}}(26)$

where $M_{y}$ is yield moment of pile section, $M_{u}$ is the ultimate moment of pile segment, $\mathrm{p}$ is the lateral pressure on pile. Once the range of $L_{p}$ has been estimated, the plastic hinge length $l_{p}$ can be set to to a fraction of $L_{p}$ for distributed plastic hinges. Generally, when the fraction is set to about 0.1 , the relative error in the ultimate displacement is acceptably small below $0.3 \%$ based on parametric studies.

\section{Seismic Analysis in Integral Abutment Bridges}

Conducted to develop building code maps, and to identify, on the regional or country scales, the points of seismic hazard with regard to destruction from earthquakes. Damage is associated with direct consequences to property or loss of function and indirect consequences such as loss of productivity or jobs [105-107]. According to Baker and Cornell [108], in order to enable prediction of economic loss from the seismic ground activity in a building or any other structural entity, there must be capability to predict how the structure will respond to various intensities of seismic activity. To evaluate the seismic performance of structures at a design site, the uncertainties in the ground motions and nonlinear structural responses need to be considered. For complicated structures such as bridges, simulation with programs seems a good way to know response structure after ground motion. 
Earthquake records with near-source ground motion characteristics, such as those of the 1994 Northridge earthquake in U.S.A., the 1995 Kobe earthquake in Japan, the 1999 Izmit and Duzce earthquake in Turkey and 1999 Chi-Chi earthquake in Taiwan, have increased the awareness of the importance of nonlinear seismic analyses employing soil foundation structure interaction on bridge structures. It has been long recognized that the IAB is highly influenced by characteristics of bridge abutments during a strong seismic excitation because of the bridge abutment interface with soil. Conventional dynamic analysis and modal pushover analysis procedures to determine seismic demands for elastic and inelastic structures have been investigated by Chopra et al. [109], who emphasize buildings. Furthermore, investigation on IAB response to seismic activity has been carried out by several researchers [110, 111]. Goel studied the characteristics of earthquakes on IAB. He assessed the dynamics of a two-span concrete bridge by recording its motions during an actual earthquake and pointed out that when there was elongation of the vibration period the damping ratio was increased by a factor of more than two when the ground motion intensity increasedSpyrakos and Loannidis [106] investigated the seismic response of a single span post-tensioned IAB and how the soil-structure interacted; they also, assessed the interaction of soil-structure with the mode shapes and how the bridge responded to the seismic movements. Sensitivity studies were done to examine the effects of the stiffness of the foundation on the general dynamics and seismic response of the bridge system. It was found that the frequency of vibration varied about $20 \%$ in extreme cases, and the stiffness of the foundation had no significant effect on how the bridge responded to the seismic activity. However, they did discover that the presence of the backfill significantly affected the dynamic characteristics and seismic response of the bridge.

Dehne and Hassiotis [112] conducted a seismic analysis on an IAB and revealed that precise modeling of the interaction of soil structure was needed to measure the impact of longitudinal and transverse earthquake movements on the response of IABs. The researchers concluded that the IAB's system with the abutment wall supported by densely compacted soil at the rear and loose sand around the piles performed best under seismic conditions.

\subsection{Time history analysis}

Dynamic loads include people, wind, waves, traffic, earthquakes, and blasts. Any structure can be subjected to dynamic loading in a lifetime. Dynamic analysis can be used to find dynamic displacements, time history, and modal analysis. A dynamic load is one that changes with time fairly quickly in comparison to the structure's natural frequency. If it changes slowly, the structure's response may be determined with static analysis, but if it varies quickly (relative to the structure's ability to respond), the response must be determined with a dynamic analysis. The ground motion parameters such as peak acceleration, peak velocities, or response spectra as developed from seismic hazard analysis, are often not sufficient to describe the effects of ground shaking. For certain structural analyses that take into account the nonlinear behavior of the structure, time history analysis is necessary. In this research, time history of ground motion that matches target ground motion parameters is artificially developed. A full-time history will give the response of structure overtime during and after the application of a load. To find the full-time history of a structure's response it must be solved the structure's equation of motion. A simple single degree of freedom system has the following equation of motion where $m$ is mass, $k$ is spring stiffness and $F(t)$ is function of load as shown in Fig. 32:

$m \ddot{x}+k x=F(t)$

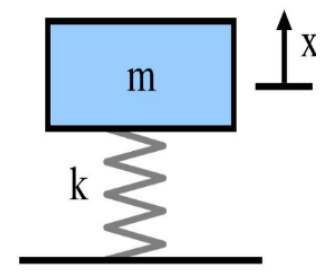

Fig. 32 Typical simple single degree of freedom system [110]

In a single degree of freedom system to find displacement of system $x$, used below equation $\omega$ obtained from equation 29. $\omega$ is frequency of system.

$x=\frac{F_{0}}{k}[1-\cos (\omega t)]$ 
$\omega=\sqrt{\frac{k}{m}}$

This gives the (theoretical) time history of the structure due to a load $F(t)$, where the false assumption is made that there is no damping. As the number of degrees of freedom of a structure increases, it very quickly becomes too difficult to calculate the time history manually. Real structures are analyzed using nonlinear finite element analysis software. In contrast to the nonlinear static procedure, the nonlinear dynamic procedure, when properly implemented, provides a more accurate calculation of the structural response to strong ground shaking. Since the nonlinear dynamic analysis model incorporates inelastic member behavior under cyclic earthquake ground motions, the nonlinear dynamic procedure explicitly simulates hysteretic energy dissipation in the nonlinear range. Only the damping in the linear range and other non-modeled energy dissipation need to be added as viscous damping [112].

\section{Conclusion}

This research paper discussed the conception of integral abutment bridges. Soil-structure interaction is reviewed in separate section, which these sections included classical theory about soil pressure behind abutment. This pressure is very effective in response to IAB. In addition, for interaction between pile and soil around it, needed to review $p$-y curve theory with different stiffness and it is necessity to use finite element modeling and seismic analysis of integral abutment bridges. However, the following major conclusions are drawn:

- Meanwhile, there are no expansion joints and bearings in an integral bridge, the abutment, its characteristics, boundary conditions, design and construction would have a greater influence on the overall behaviour of the integral bridge compared to any other components.

- $\quad$ There is no significant effect of stresses to the abutment due to vertical load. The behaviour of abutment may be greatly affected by thermal load and soil pressure. Also, thermal expansion coefficient significantly influences girder axial force, girder bending moment, pile lateral force, pile moment and pile head/abutment displacement.

- Nonlinear analysis differs significantly in magnitude compared to linear analysis. Piles will undergo non-linear deformations for thermal loading. Non-linear moment-curvature relationships for the HP piles have to be incorporated in the numerical models in order to consider the pile behavior as non-linear.

- The lateral loads imposed by the superstructure on the piles is confined within a small volume of soil around the piles.

- $\quad$ Bridge length significantly influences girder axial force, pile lateral force, pile moment and pile head displacement. The influence of bridge length on girder bending moment is relatively weak.

- $\quad$ Both lower thermal expansion coefficient and shorter bridge length are main parameters to abate IAB responses. Bridges with higher thermal expansion coefficients, shorter span lengths and stiffer piles produce positive bending moments that may reduce girder capacity.

- $\quad$ The backfill material behind the integral abutments has a significant effect on the performance of IABs. Using a compressible material behind the abutments and reinforcing the soil underlying the approach slab would enhance the in-service performance of IABs. In addition, backfill height and backfill stiffness are relatively less influential on IAB responses, but the influence of these parameters is affected by soil stiffness around piles. When soil stiffness around piles is high, backfill height inversely influences pile lateral force and pile moment. Furthermore, increase of soil stiffness around piles increases bridge bending moment, pile lateral force, pile moment and reduces pile head displacement.

7. Competing interests

The authors declare that they have no competing interests.

Author's contributions: Conceptualization, M Naji; Data curation. AA Firoozi and M Naji; Writing - original draft, AA Firoozi and M Naji; Formal analysis, M Naji; Writing - review \& editing, AA Firoozi.

Editor: Marcílio Alves. 


\section{REFERENCES}

[1] Arancibia, M.D., 2019. Design and Performance of Highly Skewed Deck Girder Bridges (Doctoral dissertation, State University of New York at Buffalo).

[2] Isopescu, B., 2016. Analysis of the behaviour of traditional carpentry joints: effects of extreme climatic conditions (Doctoral dissertation, Universidade do Minho).

[3] Giles, R.K. and Spencer Jr, B.F., 2015. Development of a long-term, multimetric structural health monitoring system for a historic steel truss swing bridge. Newmark Structural Engineering Laboratory. University of Illinois at Urbana-Champaign.

[4] Wolde-Tinsae, A.M. and Greimann, L.F., 1988. General design details for integral abutment bridges. Civil Engineering Practice, 3(2), pp.7-20.

[5] Greimann, L.F., Yang, P.S. and Wolde-Tinsae, A.M., 1986. Nonlinear analysis of integral abutment bridges. Journal of Structural Engineering, 112(10), pp.2263-2280.

[6] Lin, C.C.J., Hung, H.H., Liu, K.Y. and Chai, J.F., 2010. Reconnaissance observation on bridge damage caused by the 2008 Wenchuan (China) earthquake. Earthquake spectra, 26(4), pp.1057-1083.

[7] Greimann, L. and Wolde-Tinsae, A.M., 1988. Design model for piles in jointless bridges. Journal of Structural Engineering, 114(6), pp.1354-1371.

[8] Dicleli, M., 2000. A rational design approach for prestressed-concrete-girder integral bridges. Engineering structures, 22(3), pp.230-245.

[9] Dhar, S. and Dasgupta, K., 2019. Seismic Soil-Structure Interaction for Integral Abutment Bridges: a Review. Transportation Infrastructure Geotechnology, pp.1-19.

[10] Dicleli, M., 2016. Integral bridges. In Innovative Bridge Design Handbook (pp. 429-450). Butterworth-Heinemann.

[11] Naji, M. and Khalim, A.R., 2014. Integral Abutment Bridges-Development of Soil Model for Soil-Structure Interaction in Time History Analysis. International Journal of Engineering Research and Development, 10(3), pp.31-40.

[12] Horvath, J.S., 2005. Integral-abutment bridges: geotechnical problems and solutions using geosynthetics and ground improvement. In West Virginia University.

[13] Franchin, P. and Pinto, P.E., 2014. Performance-based seismic design of integral abutment bridges. Bulletin of earthquake engineering, 12(2), pp.939-960.

[14] LaFave, J.M., Fahnestock, L.A. and Kozak, D.L., 2018. Seismic Performance of Integral Abutment Highway Bridges in Illinois. Illinois Center for Transportation/Illinois Department of Transportation.

[15] Salman, N.N.I., 2018. Parametric Investigation of Integral Abutment Bridges: Behavior and Pile Buckling Analysis (Doctoral dissertation).

[16] Kozak, D.L., LaFave, J.M. and Fahnestock, L.A., 2018. Seismic modeling of integral abutment bridges in Illinois. Engineering Structures, 165, pp.170-183.

[17] Wang, H. and Wang, H., 2019, March. Performance Evaluation of a Two-terminal Active Inductor in the DC-link Filter of a Three-phase Diode Bridge Rectifier. In 2019 IEEE Applied Power Electronics Conference and Exposition (APEC) (pp. 2844-2848). IEEE.

[18] Briseghella, B., Huang, F. and Fiorentino, G., 2019. Seismic Behaviour of Novel Integral Abutment Bridges. NED University Journal of Research.

[19] Davids, W.G., Sandford, T., Ashley, S., DeLano, J. and Lyons, C., 2009. Field-measured response of an integral abutment bridge with short steel H-piles. Journal of Bridge Engineering, 15(1), pp.32-43.

[20] Razmi, J., 2012. Thermo-mechanical fatigue of steel piles in integral abutment bridges (Doctoral dissertation).

[21] Hällmark, R., 2006. Low-cycle fatigue of steel piles in integral abutment bridges.

[22] Lemnitzer, A., Ahlberg, E.R., Nigbor, R.L., Shamsabadi, A., Wallace, J.W. and Stewart, J.P., 2009. Lateral performance of full-scale bridge abutment wall with granular backfill. Journal of Geotechnical and Geoenvironmental Engineering, 135(4), pp.506-514. 
[23] Terzioglu, T., Jiang, D., Hueste, M.B.D. and Mander, J.B., 2016. Design and Constructability of Spread Slab-Beam Bridges. Journal of Bridge Engineering, 21(12), p.04016089.

[24] Ardeshirilajimi, A., Wu, D., Chaunsali, P., Mondal, P., Chen, Y.T., Rahman, M.M., Ibrahim, A., Lindquist, W. and Hindi, R., 2016. Bridge decks: mitigation of cracking and increased durability. Illinois Center for Transportation/Illinois Department of Transportation.

[25] Yang, P.S., Wolde-Tinsae, A.M. and Greimann, L.F., 1985. Effects of predrilling and layered soils on piles. Journal of Geotechnical Engineering, 111(1), pp.18-31.

[26] Horvath, J.S., 2004. Integral-abutment bridges: a complex soil-structure interaction challenge. In Geotechnical Engineering for Transportation Projects (pp. 460-469).

[27] Cui, L. and Mitoulis, S., 2015. DEM analysis of green rubberised backfills towards future smart integral abutment bridges (IABs). Geomechanics from Micro to Macro. I, II, pp.583-588.

[28] AASHTO, L., 2012. AASHTO LRFD bridge design specifications. American Association of State Highway and Transportation Officials, Washington, DC.

[29] Razmi, J., Ladani, L. and Aggour, M.S., 2012. Fatigue life of piles in integral-abutment bridges: Case study. Journal of Bridge Engineering, 18(10), pp.1105-1117.

[30] Abdel-Fattah, M.T. and Abdel-Fattah, T.T., 2019. Behavior of Integral Frame Abutment Bridges Due to Cyclic Thermal Loading: Nonlinear Finite-Element Analysis. Journal of Bridge Engineering, 24(5), p.04019031.

[31] Huntley, S.A. and Valsangkar, A.J., 2014. Behaviour of H-piles supporting an integral abutment bridge. Canadian Geotechnical Journal, 51(7), pp.713-734.

[32] Dowell, R.K., 2009. Closed-form moment solution for continuous beams and bridge structures. Engineering structures, 31(8), pp.1880-1887.

[33] Majka, M. and Hartnett, M., 2008. Effects of speed, load and damping on the dynamic response of railway bridges and vehicles. Computers \& Structures, 86(6), pp.556-572.

[34] Firoozi, A.A., Taha, M.R., Firoozi, A.A. and Khan, T.A., 2014. Evaluation of Physical Properties of Clays Mixed with Silica Sand (Penilaian Ciri-ciri Fizikal Tanah Liat Dicampur Pasir Silika). Jurnal Kejuruteraan (Journal of Engineering), 26, pp.77-82.

[35] Schlune, H., Plos, M. and Gylltoft, K., 2009. Improved bridge evaluation through finite element model updating using static and dynamic measurements. Engineering structures, 31(7), pp.1477-1485.

[36] Jensen, T.W., Poulsen, P.N. and Hoang, L.C., 2018. Finite element limit analysis of slabs including limitations on shear forces. Engineering Structures, 174, pp.896-905.

[37] Ribeiro, D., Calçada, R., Delgado, R., Brehm, M. and Zabel, V., 2012. Finite element model updating of a bowstring-arch railway bridge based on experimental modal parameters. Engineering Structures, 40, pp.413-435.

[38] Reccia, E., Milani, G., Cecchi, A. and Tralli, A., 2014. Full 3D homogenization approach to investigate the behavior of masonry arch bridges: The Venice trans-lagoon railway bridge. Construction and Building Materials, 66, pp.567-586.

[39] Ziolkowski, P., Poinas, P., Leszczynski, J., Karpinski, G. and Müller, E., 2010. Estimation of thermoelectric generator performance by finite element modeling. Journal of electronic materials, 39(9), pp.1934-1943.

[40] Koo, K.Y., Brownjohn, J.M.W., List, D.I. and Cole, R., 2013. Structural health monitoring of the Tamar suspension bridge. Structural Control and Health Monitoring, 20(4), pp.609-625.

[41] Jeremić, B., Kunnath, S. and Xiong, F., 2004. Influence of soil-foundation-structure interaction on seismic response of the I-880 viaduct. Engineering Structures, 26(3), pp.391-402.

[42] Fennema, J.L., Laman, J.A. and Linzell, D.G., 2005. Predicted and measured response of an integral abutment bridge. Journal of Bridge Engineering, 10(6), pp.666-677.

[43] Shamsabadi, A., Rollins, K.M. and Kapuskar, M., 2007. Nonlinear soil-abutment-bridge structure interaction for seismic performance-based design. Journal of geotechnical and geoenvironmental engineering, 133(6), pp.707-720.

[44] Clayton, C.R.I., Xu, M. and Bloodworth, A., 2006. A laboratory study of the development of earth pressure behind integral bridge abutments. Géotechnique, 56(8), pp.561-571. 
[45] Mahjoubi, S. and Maleki, S., 2018. Finite element modelling and seismic behaviour of integral abutment bridges considering soil-structure interaction. European Journal of Environmental and Civil Engineering, pp.1-20.

[46] Gorini, D.N. and Callisto, L., 2019, July. A Coupled Study of Soil-Abutment-Superstructure Interaction. In National Conference of the Researchers of Geotechnical Engineering (pp. 565-574). Springer, Cham.

[47] Gorini, D.N. and Callisto, L., 2017, June. Study of the dynamic soil-abutment-superstructure interaction for a bridge abutment. In 1st European conference on OpenSees. OpenSees days Europe (pp. 57-60).

[48] Huffman, J.T., Xiao, F., Chen, G. and Hulsey, J.L., 2015. Detection of soil-abutment interaction by monitoring bridge response using vehicle excitation. Journal of Civil Structural Health Monitoring, 5(4), pp.389-395.

[49] Mei, G.X., Chen, R. and Liu, J., 2017. New insight into developing mathematical models for predicting deformationdependent lateral earth pressure. International Journal of Geomechanics, 17(8), p.06017003.

[50] Vahedifard, F., Leshchinsky, B.A., Mortezaei, K. and Lu, N., 2015. Active earth pressures for unsaturated retaining structures. Journal of Geotechnical and Geoenvironmental Engineering, 141(11), p.04015048.

[51] Chen, J.J., Li, M.G. and Wang, J.H., 2016. Active earth pressure against rigid retaining walls subjected to confined cohesionless soil. International Journal of Geomechanics, 17(6), p.06016041.

[52] Firoozi, A.A., Olgun, C.G., Firoozi, A.A. and Baghini, M.S., 2017. Fundamentals of soil stabilization. International Journal of Geo-Engineering, 8(1), p.26.

[53] Rajesh, B.G. and Choudhury, D., 2017. Seismic passive earth resistance in submerged soils using modified pseudo-dynamic method with curved rupture surface. Marine Georesources \& Geotechnology, 35(7), pp.930-938.

[54] Hanna, A. and Diab, R., 2016. Passive earth pressure of normally and overconsolidated cohesionless soil in terms of critical-state soil mechanics parameters. International Journal of Geomechanics, 17(1), p.04016028.

[55] Pain, A., Choudhury, D. and Bhattacharyya, S.K., 2017. Seismic passive earth resistance using modified pseudo-dynamic method. Earthquake Engineering and Engineering Vibration, 16(2), pp.263-274.

[56] Zheng, Y. and Fox, P.J., 2017. Numerical investigation of the geosynthetic reinforced soil-integrated bridge system under static loading. Journal of Geotechnical and Geoenvironmental Engineering, 143(6), p.04017008.

[57] Todd, M.K., 2017. Handbook of geotechnical investigation and design tables. CRC Press.

[58] Nicks, J.E., Adams, M.T. and Li, J., 2019, March. Use of Tactile Pressure Sensors to Measure Lateral Pressures at the Face of Geosynthetic Reinforced Soil Piers. In Geo-Congress 2019: Earth Retaining Structures and Geosynthetics (pp. 212-221). Reston, VA: American Society of Civil Engineers.

[59] Liu, Z., He, F., Huang, T.Q. and Jiang, M.D., 2019. Additional earth pressure of retaining wall caused by vehicle load. Journal of highway and transportation research and development (English edition), 13(1), pp.16-23.

[60] Capilleri, P., Motta, E., Todaro, M. and Biondi, G., 2019, July. Experimental Study on a Three-Dimensional Passive Earth Pressure Coefficient in Cohesionless Soil. In National Conference of the Researchers of Geotechnical Engineering (pp. 545554). Springer, Cham

[61] Bal, A.R.L., Hoppe, U., Dang, T.S., Hackl, K. and Meschke, G., 2018. Hypoplastic particle finite element model for cutting tool-soil interaction simulations: Numerical analysis and experimental validation. Underground Space, 3(1), pp.61-71.

[62] Yazdandoust, M., Panah, A.K. and Ghalandarzadeh, A., 2019. Effect of reinforcing technique on strain-dependent dynamic properties of reinforced earth walls. Soils and Foundations.

[63] Firoozi, A.A., Firoozi, A.A. and Baghini, M.S., 2016. A Review of Clayey Soils. Asian Journal of Applied Sciences (ISSN: 23210893), 4(06).

[64] Bond, A. and Harris, A., 2006. Decoding eurocode 7. CRC Press.

[65] Griffiths, D.V. and Fenton, G.A., 2008. Risk assessment in geotechnical engineering (pp. 381-399). Hoboken, New Jersey: John Wiley \& Sons, Inc.

[66] Clough, G.W. and Duncan, J.M., 1991. Earth pressures. In Foundation engineering handbook (pp. 223-235). Springer, Boston, MA.

[67] Canadian Geotechnical Society., 1978. Canadian Foundation Engineering Manual, Montreal, Quebec. 
[68] Cole, R.T. and Rollins, K.M., 2006. Passive earth pressure mobilization during cyclic loading. Journal of Geotechnical and Geoenvironmental Engineering, 132(9), pp.1154-1164.

[69] Xu, S.Y., Kannangara, K.P.M. and Taciroglu, E., 2018. Analysis of the stress distribution across a retaining wall backfill. Computers and Geotechnics, 103, pp.13-25.

[70] Keykhosropour, L. and Lemnitzer, A., 2019. Experimental studies of seismic soil pressures on vertical flexible, underground structures and analytical comparisons. Soil Dynamics and Earthquake Engineering, 118, pp.166-178.

[71] Street, R., Woolery, E.W., Wang, Z. and Harris, J.B., 2001. NEHRP soil classifications for estimating site-dependent seismic coefficients in the Upper Mississippi Embayment. Engineering Geology, 62(1-3), pp.123-135.

[72] Lutenegger, A.J. and Saber, R.T., 1988. Determination of collapse potential of soils. Geotechnical Testing Journal, 11(3), pp.173-178.

[73] Makris, N. and Gazetas, G., 1992. Dynamic pile-soil-pile interaction. Part II: Lateral and seismic response. Earthquake engineering \& structural dynamics, 21(2), pp.145-162.

[74] Novak, M. and Nogami, T., 1977. Soil-pile interaction in horizontal vibration. Earthquake Engineering \& Structural Dynamics, 5(3), pp.263-281.

[75] Nogami, T. and Novák, M., 1976. Soil-pile interaction in vertical vibration. Earthquake Engineering \& Structural Dynamics, 4(3), pp.277-293.

[76] Su, L., Wan, H.P., Dong, Y., Frangopol, D.M. and Ling, X.Z., 2019. Seismic fragility assessment of large-scale pile-supported wharf structures considering soil-pile interaction. Engineering Structures, 186, pp.270-281.

[77] Zhang, C., Deng, P. and Ke, W., 2018. Assessing physical mechanisms related to kinematic soil-pile interaction. Soil Dynamics and Earthquake Engineering, 114, pp.22-26.

[78] Jiang, C., Zhang, Z. and He, J., 2020. Nonlinear analysis of combined loaded rigid piles in cohesionless soil slope. Computers and Geotechnics, 117, p.103225.

[79] Medjitna, L. and Amar Bouzid, D., 2019. A numerical procedure to correlate the subgrade reaction coefficient with soil stiffness properties for laterally loaded piles using the FSAFEM. International Journal of Geotechnical Engineering, 13(5), pp.458-473.

[80] Matlock, H., 1970. Correlations for design of laterally loaded piles in soft clay. Offshore technology in civil engineering's hall of fame papers from the early years, pp.77-94.

[81] Reese, L.C., 1984. Handbook on design of piles and drilled shafts under lateral load (No. FHWA-IP-84-11).

[82] Cox, W.R., Reese, L.C. and Grubbs, B.R., 1974, January. Field testing of laterally loaded piles in sand. In Offshore Technology Conference. Offshore Technology Conference.

[83] Reese, L.C., Cox, W.R. and Koop, F.D., 1974. Analysis of laterally loaded piles in sand. Offshore Technology in Civil Engineering Hall of Fame Papers from the Early Years, pp.95-105.

[84] Greimann, L.F., Wolde-Tinsae, A.M. and Yang, P.S., 1987. Finite element model for soil-pile interaction in integral abutment bridges. Computers and Geotechnics, 4(3), pp.127-149.

[85] Poulos, H.G., 1989. Pile behaviour-theory and application. Geotechnique, 39(3), pp.365-415.

[86] Chauhan, A., Litvinov, D. and Aktaa, J., 2016. Deformation and damage mechanisms of a bimodal $12 \mathrm{Cr}$-ODS steel under high-temperature cyclic loading. International Journal of Fatigue, 93, pp.1-17.

[87] Marteau, J., Bouvier, S. and Bigerelle, M., 2015. Review on numerical modeling of instrumented indentation tests for elastoplastic material behavior identification. Archives of Computational Methods in Engineering, 22(4), pp.577-593.

[88] Choi, H.Y., Lee, S.R., Park, H.I. and Kim, D.H., 2012. Evaluation of lateral load capacity of bored piles in weathered granite soil. Journal of Geotechnical and Geoenvironmental Engineering, 139(9), pp.1477-1489.

[89] Cecconi, M., Pane, V., Vecchietti, A. and Bellavita, D., 2019. Horizontal capacity of single piles: an extension of Broms' theory for $c-\varphi$ soils. Soils and Foundations.

[90] Jalbi, S., Arany, L., Salem, A., Cui, L. and Bhattacharya, S., 2019. A method to predict the cyclic loading profiles (one-way or two-way) for monopile supported offshore wind turbines. Marine Structures, 63, pp.65-83. 
[91] Yang, M., Ge, B. and Li, W., 2018. Force on the laterally loaded monopile in sandy soil. European Journal of Environmental and Civil Engineering, pp.1-20.

[92] Murchison, J.M. and O'Neill, M.W., 1984, October. Evaluation of py relationships in cohesionless soils. In Analysis and design of pile foundations (pp. 174-191). ASCE.

[93] RP2A-WSD, A.P.I., 2007. American petroleum institute recommended practice for planning, designing and constructing fixed offshore platforms-working stress design. American Petroleum Institute, Washington.

[94] Stefanidou, S.P., Sextos, A.G., Kotsoglou, A.N., Lesgidis, N. and Kappos, A.J., 2017. Soil-structure interaction effects in analysis of seismic fragility of bridges using an intensity-based ground motion selection procedure. Engineering Structures, 151, pp.366-380.

[95] Far, N.E., Maleki, S. and Barghian, M., 2015. Design of integral abutment bridges for combined thermal and seismic loads. Earthquakes and Structures, 9(2), pp.415-430.

[96] Qian, H., Wu, S., Huang, F., Zhuang, Y. and Luo, X., 2019. Modified Calculations of Lateral Displacement and Soil Pressure of Pile Considering Pile-Soil Interaction under Cyclic Loads. Journal of Testing and Evaluation, 49(4).

[97] Khatibi, S.K., Barghian, M. and Hajialilue-Bonab, M., 2019. Experimental Study of Laterally Loaded Stub Abutment and Unburied Piles. Soil Mechanics and Foundation Engineering, 55(6), pp.394-399.

[98] Li, W. and Deng, L., 2019. Axial load tests and numerical modeling of single-helix piles in cohesive and cohesionless soils. Acta Geotechnica, 14(2), pp.461-475.

[99] Zhang, J.Y. and Lei, X., 2018. Numerical modeling of parallel seismic method for detecting existing piles in layered soil. Soils and foundations, 58(1), pp.134-145.

[100] Firoozi, A.A., Firoozi, A.A. and Baghini, M.S., 2017. A review of physical and chemical clayey. J Civ Eng Urban, 6(4), pp.64-71.

[101] Hyodo, J., Shiozaki, Y., Sone, A., Ozutsumi, O. and Ichii, K., 2018. Modeling the Axial Behavior of Piles. In Developments in Earthquake Geotechnics (pp. 293-316). Springer, Cham.

[102] Khatibinia, M., Salajegheh, E., Salajegheh, J. and Fadaee, M.J., 2013. Reliability-based design optimization of reinforced concrete structures including soil-structure interaction using a discrete gravitational search algorithm and a proposed metamodel. Engineering Optimization, 45(10), pp.1147-1165.

[103] Chiou, J.S., Yang, H.H. and Chen, C.H., 2009. Use of plastic hinge model in nonlinear pushover analysis of a pile. Journal of geotechnical and geoenvironmental engineering, 135(9), pp.1341-1346.

[104] Chiou, J.S., Yang, H.H. and Chen, C.H., 2008, October. Plastic hinge setting for nonlinear pushover analysis of Pile foundations. In The 14th World Conference on Earthquake Engineering.

[105] Vasheghani-Farahani, R., Zhao, Q. and Burdette, E.G., 2010. Seismic analysis of integral abutment bridge in Tennessee, including soil-structure interaction. Transportation Research Record, 2201(1), pp.70-79.

[106] Spyrakos, C. and Loannidis, G., 2003. Seismic behavior of a post-tensioned integral bridge including soil-structure interaction (SSI). Soil Dynamics and Earthquake Engineering, 23(1), pp.53-63.

[107] Choi, B.H., Moreno, L.B., Lim, C.S., Nguyen, D.D. and Lee, T.H., 2019. Seismic Performance Evaluation of a Fully Integral Concrete Bridge with End-Restraining Abutments. Advances in Civil Engineering, 2019.

[108] Baker, J.W. and Cornell, C.A., 2008. Uncertainty propagation in probabilistic seismic loss estimation. Structural Safety, 30(3), pp.236-252.

[109] Chopra, A.K. and Goel, R.K., 2002. A modal pushover analysis procedure for estimating seismic demands for buildings. Earthquake engineering \& structural dynamics, 31(3), pp.561-582.

[110] Kotsoglou, A.N. and Pantazopoulou, S.J., 2009. Assessment and modeling of embankment participation in the seismic response of integral abutment bridges. Bulletin of Earthquake Engineering, 7(2), p.343.

[111] Mitoulis, S.A., 2012. Seismic design of bridges with the participation of seat-type abutments. Engineering Structures, 44 pp.222-233.

[112] Dehne, Y. and Hassiotis, S., 2003, July. Seismic Analysis of Integral Abutment Bridge Scotch Road I-95 Project. In Proceedings, 16th Annual ASCE Engineering Mechanics Conference. 